\title{
Sharing Economy for Cost Reduction and Efficiency Increase: The Case of Sharing E-Commerce Logistics
}

\author{
Qiang Wei $\mathbb{D}^{1},{ }^{1}$ Daguang Sun, ${ }^{2}$ Xinyu Gou, ${ }^{3}$ and Chunguang Bai $\mathbb{D}^{1}$ \\ ${ }^{1}$ School of Management and Economics, University of Electronic Science and Technology of China, Chengdu 611731, China \\ ${ }^{2}$ Southwestern University of Finance and Economics, Chengdu 611130, China \\ ${ }^{3}$ School of Business Administration, Southwestern University of Finance and Economics, Chengdu 611130, China
}

Correspondence should be addressed to Chunguang Bai; cbai@uestc.edu.cn

Received 18 February 2021; Revised 30 April 2021; Accepted 13 June 2021; Published 23 June 2021

Academic Editor: Wei Zhang

Copyright (C) 2021 Qiang Wei et al. This is an open access article distributed under the Creative Commons Attribution License, which permits unrestricted use, distribution, and reproduction in any medium, provided the original work is properly cited.

In the real business environment, due to unpredictable market demand or high prediction difficulty and low prediction accuracy, there will be inevitably operational loss in the field of e-commerce logistics caused by undersupply or oversupply of express service capabilities. At present, China is deepening the supply-side structural reforms. Confronted with the growing demand for e-commerce logistics express delivery, especially the urgent demand for tackling orders piling up to 1 billion pieces during the recent "Double 11" shopping carnival, it is very important and practical for us to study how to make scientific decisions on the supply side in the field of e-commerce express delivery. Therefore, in this paper, we design a sharing logistics cooperation mechanism considering both the undersupply and oversupply of express delivery service capabilities under stochastic demand. By comparing the earnings data of several listed express companies, we analyze four types of optimization strategies: the order flow proportion revenue sharing strategy (RE-OFP), the combined factors revenue sharing strategy (RE-RSF), the order flow proportion risk sharing strategy (RS-OFP), and the combined factors risk sharing strategy (RS-RSF). The research results demonstrate that the four optimization strategies of RE-OFP, RE-RSF, RS-OFP, and RS-RSF could achieve Pareto improvements in the operational performance of e-commerce express service. The performance of four revenue sharing and risk sharing strategies varies with different revenue sharing or risk sharing factors. Under some certain combined factors, the revenue sharing contract could help realize the supply chain coordination of the sharing logistics service. The sharing logistics cooperation mechanism based on equity investment proposed hereafter provides a feasible solution to solve the problems of high empty driving rate and operational cost of e-commerce express delivery service in urban areas.

\section{Introduction}

The sharing economy has set off a boom in China since 2017, with the emergence of business models such as shared bikes, shared cars, shared umbrellas, shared chargers, shared massages, shared travel platforms, and shared rentals. The logistics industry, especially e-commerce logistics, as a service model with a long industrial chain, multiple resource elements, and many nodes and processes, is trying to use the principles of the sharing economy in various aspects to organize production and reform itself. In recent years, typical business models of sharing logistics such as shared fleets, shared distribution, shared warehousing, shared logistics parks, and shared logistics dedicated lines have been favored by the capital market, leading to its rapid development. In other words, the sharing economy is leading in reforms and innovations at each link of the logistics chain, such as trunk transportation, urban distribution, warehousing, and logistics. With the rapid development of e-commerce in China, the daily sales volume of major e-commerce brands appears to be in a blowout state. In 2019, the number of orders processed on the "Double 11" day was as high as 1 billion. The way to optimize the supply of e-commerce logistics has practical significance and is worthy of attention. At present, many express delivery companies in China, such as ZTO, STO, YTO, and YUNDA, are coming together to jointly invest in building Cainiao Alliance to solve the problem of supply chain integration and "last mile" 
distribution through a sharing model. For example, the Cainiao courier station of the Cainiao Alliance is a network platform of logistics service for the community and campus, providing parcel collection service for users, making it a suitable example of sharing economy.

By improving the interconnectivity of logistics information, urban joint distribution can promote the intensive and large-scale development of the logistics industry, improve the utilization rate of logistics vehicles, and reduce the empty driving rate, which help to realize the goals of reducing costs and carbon emission as well as increasing the efficiency of the logistics industry. At present, China is exploring reforms and innovations in the field of logistics operation to improve the efficiency of logistics operations and reduce energy consumption in the logistics process. For example, Beijing, Chongqing, Chengdu, and Wuhan have launched joint distribution pilot projects, leading to the emergence of much more joint distribution platforms, such as Yimidida.com, Yunniao.cn, and Chengdu Panda Joint Distribution and Sichuan Swap Trailer Transport (special line) Alliance.

With the joint efforts of the government and enterprises in the market, the sharing logistics distribution model has achieved certain development. But we must clearly realize that the current level and depth of development are not enough, and many issues involve refined management of operations, and sustainable development needs to be further resolved. One way forward is collaboration between businesses, logistics service providers, and public. By working together, multiple actors crease their efficiency through sharing resources, such as vehicles, cargo consolidation or distribution centers, or last mile delivery services. Collaboration could potentially lead to fewer vehicles in urban areas, less pollution, and lower prices. However, experience from past logistics practice has shown that collaboration in city logistics projects is challenging since additional efforts of planning and control of collaboration are significant. Many operations' research contributions present solution approaches for planning and operating urban transportation systems. However, these approaches often oversimplify practice requirements and ignore challenges of synchronization between different players and modes [1]. For example, why do companies with different logistics services build a sharing logistics distribution platform? Which is feasibility, sharing or nonsharing logistics Which kind of sharing logistics mechanisms is better than another one? How to encourage the participating parties to actively maintain this kind of sharing logistics platform [2]?

To solve these problems, this paper designs an equitybased sharing logistics distribution cooperation mechanism considering both the shortage and surplus of express delivery service capacity under stochastic demand. We compare and analyze four types of optimization strategies based on the financial data of several logistics companies: revenue sharing strategy based on order flow proportion (RE-OFP), revenue sharing strategy based on combination factors (RERSF), risk sharing strategy based on order flow proportion (RS-OFP), and risk sharing strategy based on combination factors (RS-RSF). The results show that all the RE-OFP, RE-
RSF, RS-OFP, and RS-RSF could realize Pareto improvements for the operation performance of logistics service. Under different combination factors, the advantages and disadvantages of the four revenue sharing and risk sharing strategies are different, but both the revenue sharing and risk sharing strategies based on the order flow proportion and the revenue sharing and risk sharing strategies based on the combinatorial sharing factors have feasible domain spaces superior to decentralized logistics service supply chain. Revenue sharing contract could achieve the coordination of sharing logistics distribution service supply chain under specific combinatorial factors. When the combinatorial sharing factor approaches 0.5 , that is, the revenue sharing is equal, the revenue sharing and risk sharing mechanisms based on the combinatorial sharing factor are, respectively, superior to the revenue sharing and risk sharing mechanisms based on order flow proportion. This paper puts forward an equity-based sharing logistics distribution cooperation mechanism, which provides a feasible operation scheme to effectively solve the problem of high empty driving rate, high operational cost, as well as carbon emission of logistics service in urban areas.

The contributions of our study are as follows. First, we study the urban distribution problems based on the sharing economy in OM. Second, existing supply chain management research, especially supply chain coordination research, mainly analyzes the design problem of supply chain coordination contracts under specific business operational environments, mainly including buyback contract, wholesale price contract, quantity discount contract, revenue sharing contract, and risk sharing contract. Because of the coordination of various coordination contracts under different business operational background and the causal relationship of key coordination factors as well as the detailed design may change, so the traditional supply chain coordination research mainly focuses on these aspects. However, how to apply such many supply chain coordination contracts to specific business operations and how to implement these operational improvement strategies are seldom considered in previous research literatures. This paper makes interviews and exchanges with many top-class logistics enterprises and e-commerce logistics enterprises, then summarizes and refines the characteristics of business-based equity cooperation projects, which often occur in modern logistics industry, and designs the equity-based sharing logistics distribution cooperation mechanism based on these.

The rest of this paper is organized as follows. Section 2 summarizes the related literatures. Section 3 identifies the problems and hypothesis used in this paper. Section 4 discusses the benchmark model, which is the centralized and decentralized SC. We provide the revenue sharing strategy based on the OFP and RSF, respectively, in Section 5 and the risk sharing strategy based on the OFP and RSF, respectively, in Section 6. Section 7 gives some comparative analysis on the sharing logistics mechanisms. Section 8 proceeds the case study and numerical analysis and compares various optimization methods. Section 9 summarizes the managerial implications. Section 10 concludes the paper by identifying future research directions. 


\section{Literature Review}

This study focuses on logistics service supply chain and sharing mechanisms in the OM, which are mainly related to the following research streamlines: logistics service supply chain, sharing economics in the OM, and supply chain coordination. There is some literature on logistics service supply chain from different directions. The order allocation problem of logistics service supply chain composed of a logistics service integrator, and many functional logistics service providers are studied based on cumulative prospect theory [3]. A new multiobjective program scheduling model for logistics service supply chain is established by Liu et al. [4]. Liu et al. [5] discussed how the parameters inserted into the order affect the location of the customer order decoupling point when the logistics service integrator runs a mass customization logistics service. Bektas et al. [6] highlighted that innovations such as standardized containers and combined passenger and freight transportation may improve future urban delivery. Savelsbergh and Van Woensel [7] gave the most recent overview from an OR perspective, discussing trends that include the increase of e-commerce, need for speed, sustainability, sharing economy, population growth, and technological advancements. In the city logistics, long distance transports are consolidated in Urban Consolidation Centers (UCCs), and the joint operation as well as cost advantages is the crucial aspect when implementing UCCs in practice [8-10].

A key feature of sharing economy providers (SEP) is that they usually charge lower prices for the same service than traditional providers (TP) [11]. The sharing economy is decentralized and could provide new avenues for collaborative freight in urban environments. Apps and business models centered around the sharing economy are turning into an important aspect of collaborative freight [1]. Sharing economy platforms can choose from a variety of demand allocation mechanisms, from full concentration to purely market-based mechanisms. This mechanism affects how much information is displayed by service providers (such as Uber shared trips) and users and how they choose to display them to each other. For example, in the short-term rental sharing market, Airbnb, Xiaozhu, and others adopt a market-based matching mechanism, in which travelers choose potential renters and renters can decide to accept or reject the request. On the contrary, in the travel sharing market, Uber uses a centralized allocation mechanism, where passengers and drivers do not make choices, but are allocated to each other. However, Didi, the market leader in China's travel sharing market, uses a hybrid mechanism, where drivers can choose which customers to serve and passengers cannot choose drivers [12]. At present, the sharing mode of new energy fields, such as small electric fast charging and shared electric vehicles in China, relates to the company's centralized optimization in resource allocation and the consumers' independent choice of products and services in bilateral choice.

Zervas et al. [13] claimed that the core issue surrounding the sharing economy is their impact on existing companies, understanding which will help municipalities and regulators formulate appropriate laws to better regulate the sharing economy and direct existing companies' focus on marketing strategies being developed by new competitors. Cohen et al. [14] estimated that the consumer surplus created by UberX service in Chicago, Los Angeles, New York, and San Francisco was about $\$ 2.9$ billion in 2015 and $\$ 6.8$ billion in the United States as a whole. Consumer-to-consumer product sharing tends to benefit the two companies because the production capacity is relatively high compared to the cost, but the manufacturer is benefitted more than the retailer [15]. Guda and Subramanian [16] illustrated the role and effectiveness of two strategies commonly used by ondemand platforms in managing variable demand and supply conditions, namely, sharing market information with suppliers and surge pricing to solve the fundamental problem of dynamically balancing supply and demand. In general, sharing includes participation in the sharing economy driven by a variety of motives, including caring about the natural needs of others, cultural orientation, prosocial behavior, altruism, reciprocity, affiliation, pleasure, achievement, social consistency, collectivism, and the practicality and attachment of objects $[17,18]$. As of January, 2018, the number of bicycle users in China has reached 221 million and well-known brands such as Mobike, ofo, and Hello bicycles have become leading companies in this sector. A new logistics service paradigm-joint distribution is proposed [19].

Cachon et al. [20] indicated that, under the revenue sharing contract, the supplier charges the retailer a wholesale price, while obtaining a certain percentage of revenue from terminal sales. Revenue sharing contracts are popular in the cassette tape rental industry, which incentivizes retailers to increase the inventory of cassette tapes, thereby increasing the availability of popular movies. Wang et al. [21] indicated that, in a typical revenue sharing contract, the manufacturer not only charges the wholesale price per unit from the retailer but also requires to share part of the retailer's revenue. Wei et al. [22] revealed a joint optimal decision-making strategy that involves revenue sharing and cooperative investment contracts based on an order flow proportion (OFP) and a revenue sharing factor (RSF) and found that an OFP system offers the best solution in designing revenue sharing contracts based on RSFs.

Zhang et al. [23] studied the two-echelon supply chain of deteriorating items and found that the manufacturer and the retailer make joint investments in preservation technology to prevent product deterioration and design revenue sharing and cooperative investment contract to coordinate the supply chain. Revenue sharing and cost-sharing contracts are widely used in the research on sustainable supply chain and green supply chain [24-32]. Yang and Chen [28] investigated the impact of revenue sharing and cost-sharing provided by retailers on manufacturers' efforts to reduce carbon emissions and the profitability of the two companies. They also analyzed the supply chain performance under revenue sharing and investment cost-sharing independently and both together. Based on Yang and Chen [28], Li et al. [29] also analyzed supply chain performance under revenue sharing and investment cost-sharing independently or both together, but they further discussed the bargaining of supply 
chain members on the cost-sharing or revenue sharing rate. $\mathrm{Yu}$ et al. [30] discussed whether supply chain members choose revenue sharing or cost-sharing contracts in emission reduction cooperation and gave the optimal decision of supply chain members through numerical examples.

The works that are of particular relevance to our study are Zhang et al. [23], Yang and Chen [28], Wei et al. [22], and $\mathrm{Yu}$ et al. [30]. As only the implicit solution of the optimal decision can be obtained, the optimal decision is finally presented through numerical examples. Zhang et al. [23] employed revenue sharing and cost-sharing contracts to coordinate the deteriorating items' supply chain, but the coordination is not included in our study. Similar to Zhang et al. [23], our optimal decision can only be obtained by an implicit solution, and finally, a numerical example is used to choose a cooperative contract. Wei et al. [22] discussed an omni-channel supply chain structure in the joint distribution logistics cooperation model, but we focus on the omnichannel service supply chain structure considering the joint distribution cooperation mechanism under a circumstance with insufficient supply of logistics service capacity and surplus and design a mechanism of revenue sharing and cost-sharing based on equity cooperation. Yang and Chen [28] and $\mathrm{Yu}$ et al. [30] both discuss whether supply chain members choose sharing of revenue, cost, or both in emission reduction cooperation. However, we consider whether city joint distribution enterprises and many logistics companies should choose revenue sharing contract or costsharing contract to cooperate to improve the performance of logistics service supply chain.

\section{Problem Description and Hypothesis}

Considering the actual operation process, it is inevitable that there will be some difficulties in practice, such as undersupply or oversupply of express service capacity due to the asymmetry of market information and the inaccuracy of market demand forecast. This article will study the cooperative mechanism of sharing logistics under stochastic demand, with shortage and surplus of express delivery service capacity. It also compares and analyses the advantages and disadvantages of adopting revenue sharing contract and risk sharing contract under the background of equity cooperation. In order to display the results of this study as clearly as possible, we will first consider that the random demand of express service companies is relatively independent. Referring to Yun et al. [33] hypothesis about independent stochastic demand, the same hypothesis is applied to the price elasticity of demand for goods belonging to the same product category in their research literature, and it is pointed out that the price elasticity of demand for many goods is between 1 and 2 .

In addition, this paper focuses on how to cope with the risk of insufficient or excessive service caused by uncertain market requirements when express companies cooperate in equity-based sharing logistics. Therefore, we assume that each express delivery company meets the same and independent random market demand $x \sim \mathbb{U}[0, a]$, and the probability density function is $f(x)=1 / a$, and the probability function is $F(x)=\int_{0}^{x} f(x) \mathrm{d} x$. The price demand function of each express company for customer service is $p_{i}=a-q_{i}$. Among them, $q_{i}$ is the express order quantity and $p_{i}$ is the express service price. Considering the cooperation and competition relationships among express companies, the model is very complex, which makes it difficult to find a clear explicit expression. Therefore, in order to give a relatively intuitive comparative analysis result as far as possible, we assume that $i=1$ and 2 , it is to say that it focuses on the analysis of the cooperation and competition between any two express companies in a sharing logistics supply chain. At this time, the differences of the product and service among express delivery companies are mainly reflected in the price of express service $p_{i}$ and unit operating $\operatorname{cost} c_{i}$ (if $a$ has different meanings, $a_{i}, i=1$ and 2 , it means that the influence of brand awareness and service quality of express companies on customer demand is reflected in different $a_{i}$, in addition to the influence of express service price on customer demands. Since the focus of this article is not this, we assume that the cross-sectional moments of the price demand function are the same, all of which are $a$. More general information will be discussed in the following study).

At this time, the revenue of the sharing logistics distribution company based on equity cooperation is

$$
\pi_{s}=w \sum_{i=1}^{2} q_{i}-\left[c \sum_{i=1}^{2} q_{i}+e\left(\sum_{i=1}^{2} q_{i}\right)^{2}\right]
$$

where $w$ is the unit distribution service price between the sharing logistics distribution company and each express delivery company, $c$ is the unit operational cost of the sharing logistics distribution company, and $e$ is the nonscale economic cost of the sharing logistics distribution company.

For order decision-making, that is, the purchase volume of each express company, when the purchase volume is higher than the final realized customer demand, the benefits it receives in the final are the ultimate benefit of meeting customer needs, and the excess amount of purchasing orders will bear the corresponding loss of service. For the excess of urban logistics distribution service, it is possible to take emergency service measures to provide urban distribution services and obtain certain "residual value gains" (less than the price of the urban distribution service during the same period); when the purchasing quantity is lower than the demand of the express delivery service of the market, the final income obtained is determined by the quantity of the purchasing order, and the unmet market demand will bear the corresponding loss of opportunity cost. Therefore, the revenue of express delivery company $i$ can be expressed as 


$$
\begin{aligned}
\pi_{i} & =\int_{0}^{q_{i}}\left(p_{i}-w-c_{i}\right) x f(x) \mathrm{d} x+\int_{q_{i}}^{a}\left(p_{i}-w-c_{i}\right) q_{i} f(x) \mathrm{d} x \\
& =\left(p_{i}-w-c_{i}\right) \times \frac{q_{i}^{2}}{2 a}+\left(p_{i}-w-c_{i}\right) \times q_{i} \times \frac{a-q_{i}}{a} \\
& =\frac{q_{i}^{3}}{2 a}-\frac{q_{i}^{2}}{2 a}\left(3 a-w-c_{i}\right)+q_{i}\left(a-w-c_{i}\right) .
\end{aligned}
$$

The oversupply cost of express delivery company $i$ is

$$
O_{i}\left(p_{i}, q_{i}\right)=\int_{0}^{q_{i}}(w-v)\left(q_{i}-x\right) f(x) \mathrm{d} x=\frac{q_{i}^{2}}{2 a}(w-v) .
$$

In the above formula, $v$ is the unit residual value of the urban logistics distribution service. In the real business environment, it is the express delivery company which sells the excess resources of urban logistics distribution capacity to other ones which need logistics on the market and then earns the unit income. Because it is a temporary supply, the unit residual value is lower than the price of the urban logistics distribution service $w$.

The undersupply cost of express delivery company $i$ is

$$
U_{i}\left(p_{i}, q_{i}\right)=\int_{q_{i}}^{a} k\left(x-q_{i}\right) f(x) \mathrm{d} x=\frac{k q_{i}^{2}}{2 a}-k q_{i}+\frac{a k}{2} .
$$

In the above formula, $k$ is the unit opportunity cost, that is, the market demand which failed to be accurately predicted by the express delivery company. It is accurate to underestimate the market demand and cannot fully meet the service requirements caused by the market terminal demand.

The basic assumptions that need to be preset in the research process are as follows:

(1) $0<p_{i}<a, 0<q_{i}<a$, and $\forall i=1$ and 2 ; the unit service price of the express delivery company $i$ and the purchasing order quantity are both lower than $a$

(2) $k>v \geq 0$; the unit opportunity cost of express delivery company $i$ is higher than the unit residual value

The mathematical symbols shown in following Table 1 are used a lot in the research process of this article:

\section{Benchmark Model}

This section will separately study the centralized and decentralized supply chain of the sharing logistics based on equity investment. In the decentralized supply chain, we analyze two different situations. In the first situation, the sharing logistics distribution company takes the risks independently while each express delivery company independently bears the risk loss in the second situation. In a real business environment, because of the pursuit of financial performance or better market value performance of listed companies, there are indeed flexible arrangements between the vertically-holding companies to realize the cost and benefit reallocation between upstream and downstream through transfer payments in some industry chains or supply chains.

4.1. Centralized SC of the Sharing Logistics. The centralized supply chain takes the total revenue of the sharing logistics distribution company and all express delivery companies as its decision-making goal. At the same time, they share the risk loss caused by the oversupply and undersupply of express delivery services. Therefore, the overall benefit of this centralized supply chain can be expressed as

$$
\begin{aligned}
\pi_{\mathrm{sc}}^{c}= & \pi_{s}+\sum_{i=1}^{2} \pi_{i}-\sum_{i=1}^{2} O_{i}\left(p_{i}, q_{i}\right)-\sum_{i=1}^{2} U_{i}\left(p_{i}, q_{i}\right) \\
= & w \sum_{i=1}^{2} q_{i}-\left[c \sum_{i=1}^{2} q_{i}+e\left(\sum_{i=1}^{2} q_{i}\right)^{2}\right] \\
& +\sum_{i=1}^{2}\left[\int_{0}^{q_{i}}\left(p_{i}-w-c_{i}\right) x f(x) \mathrm{d} x+\int_{q_{i}}^{a}\left(p_{i}-w-c_{i}\right) q_{i} f(x) \mathrm{d} x\right. \\
& \left.-\int_{0}^{q_{i}}(w-v)\left(q_{i}-x\right) f(x) \mathrm{d} x-\int_{q_{i}}^{a} k\left(x-q_{i}\right) f(x) \mathrm{d} x\right] \\
= & w \sum_{i=1}^{2} q_{i}-\left[c \sum_{i=1}^{2} q_{i}+e\left(\sum_{i=1}^{2} q_{i}\right)^{2}\right] \\
& +\sum_{i=1}^{2}\left[\frac{q_{i}^{3}}{2 a}-\frac{q_{i}^{2}}{2 a}\left(3 a-w-c_{i}\right)+q_{i}\left(a-w-c_{i}\right)\right. \\
& \left.+q_{i}\left(a-c_{i}+k\right)-\frac{a k}{2}\right] . \\
& \left.-\frac{q_{i}^{2}}{2 a}(w-v)-\frac{k q_{i}^{2}}{2 a}+k q_{i}-\frac{a k}{2}\right] \\
= & -c \sum_{i=1}^{2} q_{i}-e\left(\sum_{i=1}^{2} q_{i}\right)^{2}+\sum_{i=1}^{2}\left[\frac{q_{i}^{3}}{2 a}-\frac{q_{i}^{2}}{2 a}\left(3 a-c_{i}-v+k\right)\right. \\
& \\
&
\end{aligned}
$$

As shown in the above formula, the decision variable of the centralized supply chain at this time is the purchase order quantity (the express delivery service price) of each express delivery company, and it is a binary cubic equation which is difficult to be solved in its explicit expression. Next, Proposition 1 will prove the existence of the optimal solution of the centralized decision and gives its implicit expression.

Proposition 1. The total revenue of the centralized supply chain of the sharing logistics based on equity investment $\pi_{s c}^{c}$ has the optimal solution $\left(p_{1}^{*}, p_{2}^{*} ; q_{1}^{*}, q_{2}^{*}\right)$, and the optimal solution satisfies 
TABle 1: Symbol description.

\begin{tabular}{|c|c|}
\hline \multicolumn{2}{|r|}{ Symbol description } \\
\hline Symbol & Meaning \\
\hline$x$ & Stochastic market demand \\
\hline$f(x)$ & Probability density function for stochastic market demand \\
\hline$F(x)$ & Probability distribution function for stochastic market demand \\
\hline$a$ & Market size \\
\hline$p_{i}$ & Unit service price of express delivery companies \\
\hline$q_{i}$ & The market service requirements for express delivery companies \\
\hline$c$ & Unit transportation cost of sharing logistics distribution service \\
\hline$e$ & Nonscale economic cost of sharing logistics distribution service \\
\hline$c_{i}$ & Intercity unit transportation cost of express delivery companies \\
\hline$w$ & $\begin{array}{c}\text { The unit service price of the sharing logistics distribution company for offering sharing delivery services to the express delivery } \\
\text { companies }\end{array}$ \\
\hline$v$ & $\begin{array}{c}\text { The unit residual value of the sharing logistics distribution service (usually the price of temporary provision of social logistics } \\
\text { services) }\end{array}$ \\
\hline$k$ & The unit opportunity cost of the sharing logistics distribution service \\
\hline$\pi_{s}$ & The revenue function of the sharing logistics distribution company \\
\hline$\pi_{i}$ & The revenue function of the express delivery company \\
\hline$O_{i}\left(p_{i}, q_{i}\right)$ & Oversupply loss \\
\hline$U_{i}\left(p_{i}, q_{i}\right)$ & Undersupply loss \\
\hline$\pi_{\mathrm{sc}}^{c}(1,1 i$ & The overall revenue of the centralized sharing logistics supply chain \\
\hline$\pi_{\mathrm{sc}}^{d}$ & The overall revenue of the decentralized sharing logistics supply chain \\
\hline$\pi_{\mathrm{sc}}^{\mathrm{sc}}$ & The overall revenue of the RE-OFP sharing logistics supply chain \\
\hline$\pi_{\mathrm{sc}}^{\mathrm{sc}}$ & The overall revenue of the RS-OFP sharing logistics supply chain \\
\hline$\pi_{\mathrm{sc}}^{\mathrm{res}}$ & The overall revenue of the RE-RSF sharing logistics supply chain \\
\hline$\pi_{\text {sc }}^{\text {sc }}$ & The overall revenue of the RS-RSF sharing logistics supply chain \\
\hline
\end{tabular}

$$
\left\{\begin{array}{l}
-c-2 e q_{2}^{*}+\frac{3 q_{1}^{* 2}}{2 a}-\frac{q_{1}^{*}}{a}\left(3 a-c_{1}-v+k+2 e a\right)+a-c_{1}+k=0, \\
-c-2 e q_{1}^{*}+\frac{3 q_{2}^{* 2}}{2 a}-\frac{q_{2}^{*}}{a}\left(3 a-c_{2}-v+k+2 e a\right)+a-c_{2}+k=0, \\
p_{i}^{*}=a-q_{i}^{*}, \quad 0<p_{i}^{*}<a \text { and } 0<q_{i}^{*}<a, i=1 \text { and } 2 .
\end{array}\right.
$$

Proof. See the Appendix.

4.2. Decentralized SC of the Sharing Logistics. In the decentralized supply chain of the sharing logistics based on equity investment, the sharing logistics distribution companies and express delivery companies, respectively, take their own profit maximization as the decision-making goal. Next, we will study the decentralized supply chain decisionmaking, while the sharing logistics distribution company takes risk loss independently, and each express delivery company independently undertakes its own risk loss caused by the undersupply and oversupply of express delivery service, which are due to its own decision-making mistakes.

4.2.1. Sharing Logistics Distribution Company Taking Risks. At this time, the sharing logistics distribution company, as the main body of the joint venture, takes the main responsibility of controlling the business risk. Therefore, its business objectives include both the maximization of expected returns and the effective control of potential risks resulting from the uncertainty of market demands. Its revenue function is

$$
\begin{aligned}
\pi_{s}^{d 1}= & w \sum_{i=1}^{2} q_{i}-\left[c \sum_{i=1}^{2} q_{i}+e\left(\sum_{i=1}^{2} q_{i}\right)^{2}\right] \\
& -\sum_{i=1}^{2}\left[\int_{0}^{q_{i}}(w-v)\left(q_{i}-x\right) f(x) \mathrm{d} x+\int_{q_{i}}^{a} k\left(x-q_{i}\right) f(x) \mathrm{d} x\right] \\
= & w \sum_{i=1}^{2} q_{i}-\left[c \sum_{i=1}^{2} q_{i}+e\left(\sum_{i=1}^{2} q_{i}\right)^{2}\right] \\
& -\sum_{i=1}^{2}\left[\frac{q_{i}^{2}}{2 a}(w-v)+\frac{k q_{i}^{2}}{2 a}-k q_{i}+\frac{a k}{2}\right] .
\end{aligned}
$$

In the above formula, the optimal decision for sharing logistics distribution company is

$$
\begin{aligned}
\frac{\partial \pi_{s}^{d 1}}{\partial q_{i}} & =w-\left(c+2 e \sum_{j=1}^{2} q_{j}\right)-\frac{w-v+k}{a} q_{i}+k=0 \\
& =>w=\frac{a c+2 a e \sum_{j=1}^{2} q_{j}+(k-v) q_{i}-a k}{a-q_{i}}, \quad \forall i=1 \text { and } 2 .
\end{aligned}
$$

According to the formula of $w$, there will be $q_{1}=q_{2}$, which means two express delivery companies have equal opportunities for cooperation. 
Thus we have

$$
w=\frac{(4 a e+k-v) q_{i}+a(c-k)}{a-q_{i}}, \quad \forall i=1 \text { and } 2 .
$$

At this point, the revenue function of the express delivery company is

$$
\begin{aligned}
\pi_{i}^{d 1} & =\int_{0}^{q_{i}}\left(p_{i}-w-c_{i}\right) x f(x) \mathrm{d} x+\int_{q_{i}}^{a}\left(p_{i}-w-c_{i}\right) q_{i} f(x) \mathrm{d} x \\
& =\frac{q_{i}^{3}}{2 a}-\frac{q_{i}^{2}}{2 a}\left(3 a-w-c_{i}\right)+q_{i}\left(a-w-c_{i}\right) .
\end{aligned}
$$

The optimal decision-making process is as follows:

$$
\begin{aligned}
\frac{\mathrm{d} \pi_{i}^{d 1}}{\mathrm{~d} q_{i}}= & \frac{3 q_{i}^{2}}{2 a}-\frac{q_{i}}{a}\left(3 a-c_{i}+4 a e+k-v\right)+\left(a-c_{i}+k-c\right) \\
& -\frac{\left[2 a q_{i}-q_{i}^{2}\right](4 a e+c-v)}{2\left(a-q_{i}\right)^{2}}=0, \quad \forall i=1 \text { and } 2, \\
= & >q_{i}^{*}=q_{i}\left(c_{i}\right), \quad \forall i=1 \text { and } 2 .
\end{aligned}
$$

But because $c_{1} \neq c_{2}$, we got

$$
=>q_{1} \neq q_{2} \text {. }
$$

Obviously, this contradicts with $q_{1}=q_{2}$ which is obtained from the previous analysis. Therefore, at this time, there is no equilibrium solution for the distributed decisionmaking mechanism for the sharing logistics distribution company taking risks. In the following, we will analyze the situation of express delivery companies taking risks.

4.2.2. Express Delivery Companies Taking Risks. At this time, each express delivery company, as the investment entity of the joint venture of the sharing logistics distribution company, will hand over the respective urban logistics distribution business to the sharing logistics distribution company and be responsible for the controlling of the business risk. At this point, the optimal decision for the sharing logistics distribution company is

$$
\begin{aligned}
\frac{\partial \pi_{s}^{d 2}}{\partial q_{i}} & =w-\left(c+2 e \sum_{j=1}^{2} q_{j}\right)=0 \\
& =>w=c+2 e \sum_{j=1}^{2} q_{j} .
\end{aligned}
$$

The business objectives of each express delivery company include both the maximization of expected returns and the effective control of operational risks caused by the market uncertainty. At this time, the revenue of each express delivery company is

$$
\begin{aligned}
\pi_{i}^{d 2}= & \pi_{i}-O_{i}\left(p_{i}, q_{i}\right)-U_{i}\left(p_{i}, q_{i}\right), \\
= & \int_{0}^{q_{i}}\left(p_{i}-w-c_{i}\right) x f(x) \mathrm{d} x+\int_{q_{i}}^{a}\left(p_{i}-w-c_{i}\right) q_{i} f(x) \mathrm{d} x \\
& -\int_{0}^{q_{i}}(w-v)\left(q_{i}-x\right) f(x) \mathrm{d} x-\int_{q_{i}}^{a} k\left(x-q_{i}\right) f(x) \mathrm{d} x, \\
= & \frac{q_{i}^{3}}{2 a}-\frac{q_{i}^{2}}{2 a}\left(3 a-w-c_{i}\right)+q_{i}\left(a-w-c_{i}\right)-\frac{q_{i}^{2}}{2 a}(w-v) \\
& -\frac{k q_{i}^{2}}{2 a}+k q_{i}-\frac{a k}{2} .
\end{aligned}
$$

As shown in the above formula, the decision variable of the decentralized supply chain at this time is the purchase order quantity (express delivery service price) of each express delivery company, and it is a binary cubic equation which is difficult to be solved in its explicit expression. Now we give the proof of the Proposition 2 to prove the existence of the optimal decision solution of the decentralized supply chain and give its implicit expression.

Proposition 2. In the decentralized supply chain of the sharing logistics in which the express delivery company independently assumes operational risks, there exists an optimal solution $\left(p_{i}^{*}, q_{i}^{*}\right)$ for the revenue function $\pi_{i}^{d 2}$ of express company $i$, and the optimal solution satisfies

$$
\left\{\begin{array}{l}
-c-2 e q_{1}^{*}+\frac{3 q_{2}^{* 2}}{2 a}-\frac{q_{2}^{*}}{a}\left(3 a-c_{2}-v+k+4 e a\right)+a-c_{2}+k=0, \\
-c-2 e q_{2}^{*}+\frac{3 q_{1}^{* 2}}{2 a}-\frac{q_{1}^{*}}{a}\left(3 a-c_{1}-v+k+4 e a\right)+a-c_{1}+k=0, \\
p_{i}^{*}=a-q_{i}^{*}, \quad 0<p_{i}^{*}<a \text { and } 0<q_{i}^{*}<a, i=1 \text { and } 2 .
\end{array}\right.
$$

Proof. See the Appendix.

It proves that there are both cooperative and competitive relationships among express delivery companies at this time. On the one hand, they cooperate to establish a sharing logistics distribution company, and on the other hand, they compete when deciding their respective express delivery service supply. Therefore, its decision-making thought is similar to the Cournot game. Firstly, we will solve the optimal response of the purchase order decision of each express delivery company to the order decision of other express delivery companies and then solve the equilibrium solutions of these optimal responses. But because the optimal response curve is a quadratic equation, for the dual channel structure composed of two express companies, the final solution equation at this time is a quaternary equation of one variable, and it is difficult to give explicit expressions. However, it is 
clear that the optimal decision of purchase order quantity meets the above conditions.

\section{SC of the Sharing Logistics with Revenue- Sharing}

According to the analysis of the decentralized supply chain of sharing logistics, it is feasible for each express delivery company taking risks. On the contrary, there is no possibility of existence of the sharing logistics distribution company bearing the risk together. Therefore, in the process of classification discussion of the sharing logistics supply chain with revenue sharing strategy, it is only necessary to consider the situation in which each express delivery company bears its own business risk. At this point, the optimal decision of the sharing logistics distribution company is always

$$
\begin{aligned}
\frac{\partial \pi_{s}^{\mathrm{re}}}{\partial q_{i}} & =w-\left(c+2 e \sum_{j=1}^{2} q_{j}\right)=0 \\
& =>w=c+2 e \sum_{j=1}^{2} q_{j} .
\end{aligned}
$$

5.1. Revenue-Sharing Based on the OFP: RE-OFP. In the order flow proportion revenuesharing supply chain, each express delivery company determines the mutual benefit of each other according to the proportion of their respective order flow contributions. The order flow proportion is

$$
\left(\frac{q_{1}}{\sum_{j=1}^{2} q_{j}}, \frac{q_{2}}{\sum_{j=1}^{2} q_{j}}\right) \text {. }
$$

At this time, the revenue of each express delivery company includes both the part of the operational risk as well as the OFP share of the revenue of the sharing logistics distribution company. Therefore, the revenue function is

$$
\begin{aligned}
\pi_{i}^{\mathrm{ref}}= & \pi_{i}-O_{i}\left(p_{i}, q_{i}\right)-U_{i}\left(p_{i}, q_{i}\right) \\
& +\frac{q_{i}}{\sum_{j=1}^{2} q_{j}}\left\{w \sum_{j=1}^{2} q_{j}-\left[c \sum_{j=1}^{2} q_{j}+e\left(\sum_{j=1}^{2} q_{j}\right)^{2}\right]\right\}, \\
= & \int_{0}^{q_{i}}\left(p_{i}-w-c_{i}\right) x f(x) \mathrm{d} x+\int_{q_{i}}^{a}\left(p_{i}-w-c_{i}\right) q_{i} f(x) \mathrm{d} x \\
& -\int_{0}^{q_{i}}(w-v)\left(q_{i}-x\right) f(x) \mathrm{d} x-\int_{q_{i}}^{a} k\left(x-q_{i}\right) f(x) \mathrm{d} x \\
& +\frac{q_{i}}{\sum_{j=1}^{2} q_{j}}\left\{w \sum_{j=1}^{2} q_{j}-\left[c \sum_{j=1}^{2} q_{j}+e\left(\sum_{j=1}^{2} q_{j}\right)^{2}\right]\right\}, \\
= & \frac{q_{i}^{3}}{2 a}-\frac{q_{i}^{2}}{2 a}\left(3 a-c_{i}-v+k\right)+q_{i}\left(a-c_{i}+k-c-e \sum_{j=1}^{2} q_{j}\right)-\frac{a k}{2} .
\end{aligned}
$$

As shown in the above formula, the decision variable of the sharing logistics supply chain with OFP revenue sharing strategy is the purchase order quantity (express delivery service price) of each express delivery company. And, it is a binary cubic equation, so it is difficult to be solved in its explicit expression. Next, we use Proposition 3 to prove the existence of the optimal decision solution of the revenue sharing supply chain and give its implicit expression.

Proposition 3. In the OFP revenue sharing supply chain of the sharing logistics, the revenue function $\pi_{i}^{\text {ref }}$ of the express delivery company $i$ has an optimal solution $\left(p_{i}^{*}, q_{i}^{*}\right)$, and the optimal solution satisfies

$$
\left\{\begin{array}{l}
-c-e q_{1}^{*}+\frac{3 q_{2}^{* 2}}{2 a}-\frac{q_{2}^{*}}{a}\left(3 a-c_{2}-v+k+2 e a\right)+a-c_{2}+k=0, \\
-c-e q_{2}^{*}+\frac{3 q_{1}^{* 2}}{2 a}-\frac{q_{1}^{*}}{a}\left(3 a-c_{1}-v+k+2 e a\right)+a-c_{1}+k=0, \\
p_{i}^{*}=a-q_{i}^{*}, \quad 0<p_{i}^{*}<a \text { and } 0<q_{i}^{*}<a, i=1 \text { and } 2 .
\end{array}\right.
$$

Proof. See the Appendix.

At this time, each express delivery company has a relationship of both cooperation and competition. On the one hand, they will work together to establish a sharing logistics distribution company, and on the other hand, they will simultaneously compete in the decision-making of their respective express service supply. Therefore, the decisionmaking idea is similar to the Cournot game. Firstly, the optimal response of the purchase order decision of each express delivery company to the purchase order decision of other express delivery companies is solved, and then, the equilibrium solution of these optimal responses is solved. However, because the optimal response curve is a quadratic equation, for the dual channel supply chain structure composed of two express companies, the final solution equation at this time is a quaternary equation of one variable, and it is difficult to give a dominant expression. However, it is clear that the optimal decision of purchase order quantity satisfies the above conditions.

5.2. Revenue-Sharing Based on the RSF: RE-RSF. In the combined sharing factor revenue sharing supply chain, each express delivery company determines the mutual benefit of each other according to the combination sharing factor. Among them, it is assumed that this sharing factor combination is

$$
\left(\gamma_{1}^{\mathrm{res}}, \gamma_{2}^{\mathrm{res}}\right) \quad \gamma_{i}^{\mathrm{res}} \in[0,1] \text { and } \sum_{i=1}^{2} \gamma_{i}^{\mathrm{res}}=1 .
$$

At this point, the revenue of each express delivery company not only includes the part of business risk but also includes the part of revenue sharing based on the combined sharing factors. Thus, its revenue function is 


$$
\begin{aligned}
\pi_{i}^{\mathrm{res}}= & \pi_{i}-O_{i}\left(p_{i}, q_{i}\right)-U_{i}\left(p_{i}, q_{i}\right)+\gamma_{i}^{\mathrm{res}}\left\{w \sum_{j=1}^{2} q_{j}-\left[c \sum_{j=1}^{2} q_{j}+e\left(\sum_{j=1}^{2} q_{j}\right)^{2}\right]\right\}, \\
= & \int_{0}^{q_{i}}\left(p_{i}-w-c_{i}\right) x f(x) \mathrm{d} x+\int_{q_{i}}^{a}\left(p_{i}-w-c_{i}\right) q_{i} f(x) \mathrm{d} x \\
& -\int_{0}^{q_{i}}(w-v)\left(q_{i}-x\right) f(x) \mathrm{d} x-\int_{q_{i}}^{a} k\left(x-q_{i}\right) f(x) \mathrm{d} x+\gamma_{i}^{\text {res }}\left\{w \sum_{j=1}^{2} q_{j}-\left[c \sum_{j=1}^{2} q_{j}+e\left(\sum_{j=1}^{2} q_{j}\right)^{2}\right]\right\}, \\
= & \frac{q_{i}^{3}}{2 a}-\frac{q_{i}^{2}}{2 a}\left(3 a-c_{i}-v+k\right)+q_{i}\left(a-c_{i}+k-c-2 e \sum_{j=1}^{2} q_{j}\right)-\frac{a k}{2}+\gamma_{i}^{r e s} e\left(\sum_{j=1}^{2} q_{j}\right)^{2} .
\end{aligned}
$$

As shown in the above formula, at this time, the decision variable of the combination sharing factor revenue sharing supply chain is the purchase order quantity (express delivery service price) of each express delivery company, and it is a binary cubic equation which is difficult to be solved in its explicit expression. Next, we use Proposition 4 to prove the existence of the optimal decision solution of the revenue sharing supply chain and give its implicit expression.

Proposition 4. In the RSF revenue sharing supply chain of the sharing logistics, the revenue function $\pi_{i}^{\text {res }}$ of the express delivery company $i$ has an optimal solution $\left(p_{i}^{*}, q_{i}^{*}\right)$, and the optimal solution satisfies

$$
\left\{\begin{array}{l}
-c-2\left(1-\gamma_{2}^{\mathrm{res}}\right) e q_{1}^{*}+\frac{3 q_{2}^{* 2}}{2 a}-\frac{q_{2}^{*}}{a}\left(3 a-c_{2}-v+k+4 e a-2 \gamma_{2}^{\mathrm{res}} e a\right)+a-c_{2}+k=0 \\
-c-2\left(1-\gamma_{1}^{\mathrm{res}}\right) e q_{2}^{*}+\frac{3 q_{1}^{* 2}}{2 a}-\frac{q_{1}^{*}}{a}\left(3 a-c_{1}-v+k+4 e a-2 \gamma_{1}^{\mathrm{res}} e a\right)+a-c_{1}+k=0 \\
p_{i}^{*}=a-q_{i}^{*}, \quad 0<p_{i}^{*}<a \text { and } 0<q_{i}^{*}<a, i=1 \text { and } 2 .
\end{array}\right.
$$

Proof. See the Appendix.

At this time, each express delivery company has a relationship of both cooperation and competition. On the one hand, they cooperate to establish a sharing logistics distribution company, and on the other hand, they also have a competitive relationship when deciding its own supply of express delivery services. Therefore, the decision-making idea is similar to the Cournot game. Firstly, we calculate the optimal response based on the impact of the purchase order decision of each express company on the purchase order decision of other express companies, and then, we solve the equilibrium solution of these optimal responses. However, because the optimal response curve is a quadratic equation, for the dual channel supply chain structure composed of two express companies, the final solution equation at this time is a quaternary equation of one variable, and it is difficult to give a dominant expression. However, it is clear that the optimal decision purchase order quantity satisfies the above conditions.

\section{SC of the Sharing Logistics with Risk Sharing}

According to the analysis of the decentralized supply chain of sharing logistics, it is feasible for each express delivery company to take risks. On the contrary, it is not feasible for the sharing logistics distribution company to share the risks. Therefore, in the process of classification discussion of risk sharing supply chain, it is only necessary to consider the situation in which each express delivery company bears its own business risk. Therefore, the optimal decision of the sharing logistics distribution company is always

$$
\begin{aligned}
\frac{\partial \pi_{s}^{\mathrm{re}}}{\partial q_{i}} & =w-\left(c+2 e \sum_{j=1}^{2} q_{j}\right)=0, \\
& =>w=c+2 e \sum_{j=1}^{2} q_{j} .
\end{aligned}
$$


6.1. Risk Sharing Based on the OFP: RS-OFP. In the order flow proportion risk sharing supply chain of sharing logistics, each express delivery company determines the risk sharing of each other according to their respective order flow contribution. Among them, the proportion of their respective order flows is

$$
\left(\frac{q_{1}}{\sum_{j=1}^{2} q_{j}}, \frac{q_{2}}{\sum_{j=1}^{2} q_{j}}\right)
$$

At this point, the revenue of the express delivery company is

$$
\begin{aligned}
\pi_{i}^{\mathrm{rsf}}= & \pi_{i}-\frac{q_{i}}{\sum_{j=1}^{2} q_{j}} \sum_{j=1}^{2}\left[O_{i}\left(p_{i}, q_{i}\right)+U_{i}\left(p_{i}, q_{i}\right)\right], \\
= & \int_{0}^{q_{i}}\left(p_{i}-w-c_{i}\right) x f(x) \mathrm{d} x+\int_{q_{i}}^{a}\left(p_{i}-w-c_{i}\right) q_{i} f(x) \mathrm{d} x \\
& -\frac{q_{i}}{\sum_{j=1}^{2} q_{j}} \sum_{j=1}^{2}\left[\int_{0}^{q_{i}}(w-v)\left(q_{i}-x\right) f(x) \mathrm{d} x+\int_{q_{i}}^{a} k\left(x-q_{i}\right) f(x) \mathrm{d} x\right], \\
= & \frac{q_{i}^{3}}{2 a}-\frac{q_{i}^{2}}{2 a}\left(3 a-c_{i}-w\right)+q_{i}\left(a-c_{i}-w\right)-\frac{q_{i}}{\sum_{j=1}^{2} q_{j}} \sum_{j=1}^{2}\left[\frac{q_{j}^{2}}{2 a}(w-v)+\frac{k q_{j}^{2}}{2 a}-k q_{i}+\frac{a k}{2}\right] .
\end{aligned}
$$

As shown in the above formula, the decision variable at this time is the purchase order quantity (express delivery service price) of each express delivery company, and it is a binary cubic equation which is difficult to be solved in its explicit expression. Next, we use Proposition 5 to prove the existence of the optimal decision solution of the risk sharing supply chain and give its implicit expression.
Proposition 5. In the OFP risk sharing supply chain of sharing logistics, the revenue function $\pi_{i}^{r s f}$ of the express delivery company $i$ has an optimal solution $\left(p_{i}^{*}, q_{i}^{*}\right)$, and the optimal solution satisfies

$$
\left\{\begin{array}{l}
-c-4 e q_{1}^{*}+\frac{(3+6 e) q_{1}^{* 2}}{2 a}-\frac{q_{1}^{*}}{a}\left(3 a-c-c_{1}-2 e q_{2}^{*}\right)+a-c_{1}-2 e q_{2}^{*}-\frac{q_{2}^{*}}{\left(q_{1}^{*}+q_{2}^{*}\right)^{2}} \\
\sum_{j=1}^{2}\left[\frac{q_{j}^{* 2}}{2 a}\left(c-v+k+2 e \sum_{j=1}^{2} q_{j}^{*}\right)-k q_{j}^{*}+\frac{a k}{2}\right]-\frac{q_{1}^{*}}{q_{1}^{*}+q_{2}^{*}}\left[\frac{q_{1}^{*}\left(c-v+k+2 e \sum_{j=1}^{2} q_{j}^{*}\right)}{a}-k+\frac{e\left(q_{1}^{* 2}+q_{2}^{* 2}\right)}{a}\right]=0, \\
-c-4 e q_{2}^{*}+\frac{(3+6 e) q_{2}^{* 2}}{2 a}-\frac{q_{2}^{*}}{a}\left(3 a-c-c_{2}-2 e q_{1}^{*}\right)+a-c_{2}-2 e q_{1}^{*}-\frac{q_{1}^{*}}{\left(q_{1}^{*}+q_{2}^{*}\right)^{2}} \\
\sum_{j=1}^{2}\left[\frac{q_{j}^{* 2}}{2 a}\left(c-v+k+2 e \sum_{j=1}^{2} q_{j}^{*}\right)-k q_{j}^{*}+\frac{a k}{2}\right]-\frac{q_{2}^{*}}{q_{1}^{*}+q_{2}^{*}}\left[\frac{q_{2}^{*}\left(c-v+k+2 e \sum_{j=1}^{2} q_{j}^{*}\right)}{a}-k+\frac{e\left(q_{1}^{* 2}+q_{2}^{* 2}\right)}{a}\right]=0 \\
p_{i}^{*}=a-q_{i}^{*}, \quad 0<p_{i}^{*}<a \text { and } 0<q_{i}^{*}<a, i=1 \text { and } 2 .
\end{array}\right.
$$

Proof. See the Appendix.

At this time, each express delivery company has a relationship of both cooperation and competition. On the one hand, they cooperate to establish a sharing logistics distribution company, and on the other hand, they also have a competitive relationship when deciding their respective express delivery service supply. Therefore, the idea of decision-making is similar to Cournot game. First, we calculate the optimal response based on the impact of the purchase order decision of each express company on the purchase 
order decision of other express companies, and then, we solve the equilibrium solution of these optimal responses. However, because the optimal response curve is a quadratic equation, for the dual channel supply chain structure composed of two express companies, the final solution equation at this time is a quaternary equation of one variable, and it is difficult to give a dominant expression. However, it is clear that the optimal decision purchase order quantity satisfies the above conditions.

6.2. Risk Sharing Based on the RSF: RS-RSF. In the combined sharing factor risk sharing supply chain of sharing logistics, each express delivery company determines the risk sharing of each other according to the combination factor. Among them, the risk sharing factor combination is

$$
\left(\gamma_{1}^{\mathrm{rss}}, \gamma_{2}^{\mathrm{rss}}\right) \quad \gamma_{i}^{\mathrm{rss}} \in[0,1] \text { and } \sum_{i=1}^{2} \gamma_{i}^{\mathrm{rss}}=1 .
$$

At this point, the revenue of the express delivery company is

$$
\begin{aligned}
\pi_{i}^{\mathrm{rss}}= & \pi_{i}-\gamma_{i}^{\mathrm{rss}} \sum_{j=1}^{2}\left[O_{j}\left(p_{j}, q_{j}\right)+U_{j}\left(p_{j}, q_{j}\right)\right] \\
= & \int_{0}^{q_{i}}\left(p_{i}-w-c_{i}\right) x f(x) \mathrm{d} x+\int_{q_{i}}^{a}\left(p_{i}-w-c_{i}\right) q_{i} f(x) \mathrm{d} x \\
& -\gamma_{i}^{\mathrm{rss}} \sum_{j=1}^{2}\left[\int_{0}^{q_{j}}(w-v)\left(q_{j}-x\right) f(x) \mathrm{d} x\right. \\
& \left.+\int_{q_{j}}^{a} k\left(x-q_{j}\right) f(x) \mathrm{d} x\right] \\
= & \frac{q_{i}^{3}}{2 a}-\frac{q_{i}^{2}}{2 a}\left(3 a-c_{i}-w\right)+q_{i}\left(a-c_{i}-w\right) \\
& -\gamma_{i}^{\mathrm{rss}} \sum_{j=1}^{2}\left[\frac{q_{j}^{2}}{2 a}(w-v)+\frac{k q_{j}^{2}}{2 a}-k q_{j}+\frac{a k}{2}\right] .
\end{aligned}
$$

As shown in the above formula, the decision variable of the combined sharing factor risk sharing supply chain at this time is the purchase order quantity (express delivery service price) of each express delivery company, and it is a binary cubic equation which is difficult to be solved in its explicit expression. Next, we use Proposition 6 to prove the existence of the optimal decision solution of the risk sharing supply chain and give its implicit expression.

Proposition 6. In the RSF risk sharing supply chain of sharing logistics, the revenue function $\pi_{i}^{\text {rss }}$ of the express delivery company $i$ has an optimal solution $\left(p_{i}^{*}, q_{i}^{*}\right)$, and the optimal solution satisfies

$$
\left\{\begin{array}{l}
-c-4 e q_{1}^{*}+\frac{(3+6 e) q_{1}^{* 2}}{2 a}-\frac{q_{1}^{*}}{a}\left(3 a-c_{1}-c-2 e q_{2}^{*}\right)+a-c_{1}-2 e q_{2}^{*} \\
-\gamma_{1}^{\mathrm{rss}}\left[\frac{q_{1}^{*}\left(c-v+k+2 e \sum_{j=1}^{2} q_{j}^{*}\right)}{a}-k+\frac{e\left(q_{1}^{* 2}+q_{2}^{* 2}\right)}{a}\right]=0, \\
-c-4 e q_{2}^{*}+\frac{(3+6 e) q_{2}^{* 2}}{2 a}-\frac{q_{2}^{*}}{a}\left(3 a-c_{2}-c-2 e q_{1}^{*}\right)+a-c_{2}-2 e q_{1}^{*} \\
-\gamma_{2}^{r s s}\left[\frac{q_{2}^{*}\left(c-v+k+2 e \sum_{j=1}^{2} q_{j}^{*}\right)}{a}-k+\frac{e\left(q_{1}^{* 2}+q_{2}^{* 2}\right)}{a}\right]=0, \\
p_{i}^{*}=a-q_{i}^{*}, \quad 0<p_{i}^{*}<a \text { and } 0<q_{i}^{*}<a, i=1 \text { and } 2 .
\end{array}\right.
$$

Proof. See the Appendix.

At this time, each express delivery company has both a cooperative relationship and a competitive relationship. On the one hand, they cooperate to establish a sharing logistics distribution company, and on the other hand, they also have a competitive relationship when deciding its own supply of express delivery services. Therefore, the decision-making idea is similar to the Cournot game. First, we calculate the optimal response based on the impact of the purchase order decision of each express company on the purchase order decision of other express companies, and then, we solve the equilibrium solution of these optimal responses. However, because the optimal response curve is a quadratic equation, for the dual channel supply chain structure composed of two express companies, the final solution equation at this time is a quaternary equation of one variable, and it is difficult to give a dominant expression. However, it is clear that the optimal decision purchase order quantity satisfies the above conditions.

\section{Comparative Analysis}

According to Propositions 1-6, we see that all the optimal decision variables $p_{i}$ and $q_{i}$ can be solved through a quaternion equation of one variable as following Lemma 1 shows. However, the solution expression of a quartic equation in one variable is very complicated, and it is difficult to give a clear comparative analysis result. We will give some comparative analysis results in this section, while the others will be analyzed through the case study and numerical analysis in following Section 8 .

Lemma 1. For a standard unary quartic equation $\widehat{a} z^{4}+\widehat{b} z^{3}+\widehat{c} z^{2}+\widehat{d} z+\widehat{e}=0$, we can solve the variable $z$ as follows:

$$
\begin{aligned}
& \text { Set } \widehat{P}=\left(\widehat{c}^{2}+12 \widehat{a} \widehat{e}-3 \widehat{b} \widehat{d}\right) / 9, \widehat{Q}=\left(27 \widehat{a} \widehat{d}^{2}+2 \widehat{c}^{3}+27 \widehat{b}^{2} \widehat{e}\right. \\
& -72 \widehat{a} \widehat{c} \widehat{e}-9 \widehat{b} \widehat{c} \widehat{d}) / 54 \text {, and } \widehat{D}=\sqrt{\widehat{Q}^{2}-\widehat{P}^{3}} \text {. We have }
\end{aligned}
$$


$\widehat{u}= \begin{cases}\sqrt[3]{\widehat{Q}+\widehat{D}}, & \text { if }|\widehat{Q}-\widehat{D}| \leq|\widehat{Q}+\widehat{D}|, \\ \sqrt[3]{\widehat{Q}-\widehat{D}}, & \text { else }|\widehat{Q}-\widehat{D}|>|\widehat{Q}+\widehat{D}|\end{cases}$

$$
\widehat{v}= \begin{cases}0, & \text { if } \widehat{u}=0, \\ \frac{\widehat{P}}{\widehat{u}}, & \text { else. }\end{cases}
$$

\begin{tabular}{|c|c|}
\hline Make & $\widehat{w}=-(1 / 2)+(\sqrt{3} / 2) i$ \\
\hline
\end{tabular}

For $k=0,1$, and 2 , solve the value of $\widehat{m}$. If all the three values of $\hat{m}$ are zero, we have

$$
\begin{aligned}
& \widehat{S}=\widehat{b}^{2}-\frac{8 \widehat{a} \widehat{c}}{3}, \\
& \widehat{T}=0 .
\end{aligned}
$$

Else if $k=\operatorname{argmax}_{k}|\widehat{m}|$, we have

$$
\begin{aligned}
& \widehat{S}=2 \widehat{b}^{2}-\frac{16 \widehat{a} \widehat{c}}{3}-4 \widehat{a}\left(\widehat{w}^{k} \widehat{u}+\widehat{w}^{3-k} \widehat{v}\right), \\
& \widehat{T}=\frac{8 \widehat{a} \widehat{b} \widehat{c}-16 \widehat{a}^{2} \widehat{d}-2 \widehat{b}^{3}}{\widehat{m}} .
\end{aligned}
$$

Therefore, the decision variable will be

$$
\begin{aligned}
& z 1=\frac{-\widehat{b}-\widehat{m}+\sqrt{\widehat{S}-\widehat{T}}}{4 \widehat{a}}, \\
& z 2=\frac{-\widehat{b}-\widehat{m}-\sqrt{\widehat{S}-\widehat{T}}}{4 \widehat{a}}, \\
& z 3=\frac{-\widehat{b}+\widehat{m}+\sqrt{\widehat{S}+\widehat{T}}}{4 \widehat{a}}, \\
& z 4=\frac{-\widehat{b}+\widehat{m}-\sqrt{\widehat{S}+\widehat{T}}}{4 \widehat{a}} .
\end{aligned}
$$

Next, we will give some comparative analysis results according to Propositions 1-6 as the following corollary shows.

Corollary 1. If $c_{1}=c_{2}$, which means the express companies are completely homogeneous, we have $\max \left\{q_{1}^{*}, q_{2}^{*} \mid\right.$ ref $\}<$ $\max \left\{q_{1}^{*}, q_{2}^{*} \mid c\right\}<\max \left\{q_{1}^{*}, q_{2}^{*} \mid d_{2}\right\}$.

Corollary 1 demonstrates that when the two express delivery companies are completely homogeneous, the optimal order quantity in the centralized SC is bigger than that in the SC of sharing logistics with revenue sharing based on the OFP, while not bigger than that in the decentralized SC with express delivery companies taking risks.

Example 1. $a=10, c=1, e=1, v=2$, and $k=2.5$.
According to the visualization in Figure $1, \max \left\{q_{1}^{*}, q_{2}^{*}\right\}$ ref $\}<\max \left\{q_{1}^{*}, q_{2}^{*} \mid c\right\}<\max \left\{q_{1}^{*}, q_{2}^{*} \mid d_{2}\right\}$ satisfies when the variables $a=10, c=1, e=1, v=2$, and $k=2.5$.

Corollary 2. If $\gamma_{1}^{\text {res }}=\gamma_{2}^{\text {res }}=1 / 2$, which means the express companies distribute income equally from the sharing logistics distribution company, we have $q_{i}^{*} \mid$ res $=q_{i}^{*} \mid c, i=1$ and 2 ; $\pi_{1}^{\text {res } *}=\pi_{2}^{\text {res } *}=(1 / 2) \pi_{s c}^{c *}$.

Corollary 2 demonstrates that when the two express delivery companies distribute income equally from the sharing logistics distribution company in the SC of sharing logistics with revenue sharing based on the RSF, the optimal order quantity $q_{i}$ in the SC of sharing logistics with revenue sharing based on the RSF is equal to that in the centralized SC. It means that the sharing logistics mechanism achieves the optimal supply chain coordination.

Corollary 3. To compare and analyze the income gap between express delivery companies before and after the implementation of sharing logistics, it should be considered that, before the implementation of sharing logistics, each express delivery company only runs intercity logistics transportation services, and all urban logistics distribution services are outsourced, so the calculation of its income needs to deduct the cost of urban logistics distribution. After the implementation of sharing logistics, the effect of vertical integration has been produced, and the operational boundaries of express delivery companies have increased. In addition to intercity logistics transportation revenues, there are also urban logistics distribution revenues.

\section{Case Study}

8.1. Data Source. As a subdivision of the modern logistics industry, e-commerce logistics express delivery has gradually standardized the logistics operation costs between provinces or economic zones and has been well optimized and improved. However, in the wider urban logistics sector, due to the different characteristics of industrial structures in various regions, the flow direction and flow of materials in the logistics industry exhibit a highly nonequilibrium character. Moreover, most e-commerce express delivery companies and even large-scale urban logistics distribution companies still adopt the traditional franchise business model in the city level, and it is difficult to achieve centralized and unified management and control of operating costs; for this reason, the cost of first-line logistics in various regions is often very different. In view of this, in order to study more general issues and explain the general results, the data used in the case study and numerical analysis of this paper mainly comes from the previous years' earnings data of several listed express delivery companies $[22,34]$. At the same time, it combines research and interviews on the actual operation of some e-commerce express delivery companies and related cost information. We will mainly use the data listed in Table 2 and 3. 


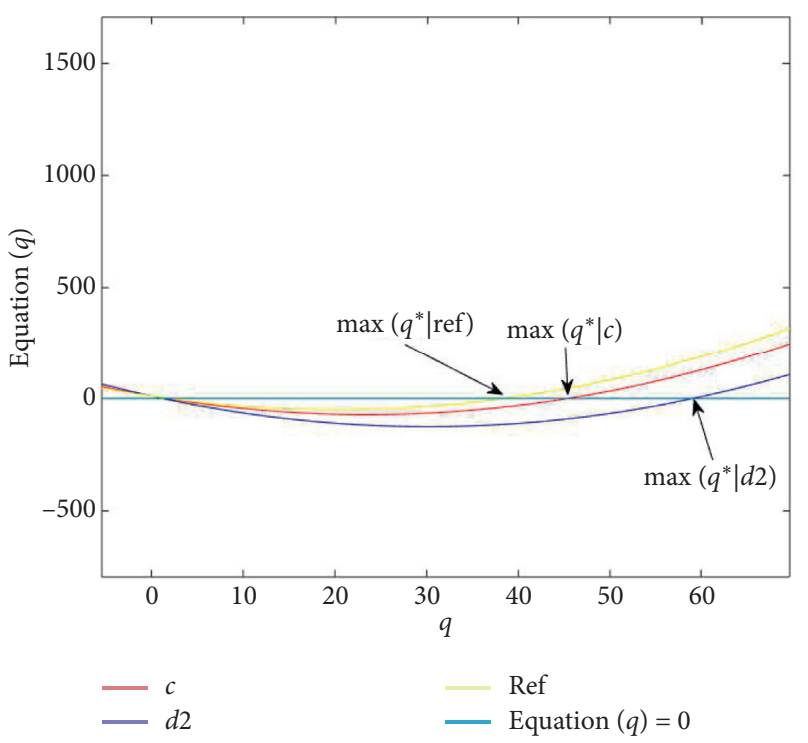

Figure 1: Example of Corollary 1.

TABLE 2: Market size and market share data of listed express delivery companies.

\begin{tabular}{|c|c|c|c|c|}
\hline \multirow[t]{2}{*}{ Total market size } & \multicolumn{4}{|c|}{ Market share } \\
\hline & STO Express & YTO Express & YUNDA Express & ZTO Express \\
\hline \multirow{4}{*}{19894417401} & 0.196364433 & 0.254281639 & 0.236758698 & 0.312595231 \\
\hline & \multicolumn{4}{|c|}{ Market size } \\
\hline & STO Express & YTO Express & YUNDA Express & ZTO Express \\
\hline & 3906555984 & 5058785063 & 4710176354 & 6218900000 \\
\hline
\end{tabular}

TABle 3: Operating cost data of listed express delivery companies.

\begin{tabular}{|c|c|c|c|c|}
\hline Unit cost of sharing logistics distribution & \multicolumn{4}{|c|}{$\begin{array}{c}c \\
1.50\end{array}$} \\
\hline Nonscale economic cost & \multicolumn{4}{|c|}{$\stackrel{e}{\longrightarrow} 0.11$} \\
\hline Unit transportation cost & $\begin{array}{c}\text { STO Express } \\
1.00\end{array}$ & $\begin{array}{c}\text { YTO Express } \\
1.13\end{array}$ & $\begin{array}{c}\text { YUNDA Express } \\
1.02\end{array}$ & $\begin{array}{c}\text { ZTO Express } \\
0.93\end{array}$ \\
\hline
\end{tabular}

According to Table 2, the total express delivery market of the four listed express delivery companies is about 19.894 billion. Moreover, the market share of STO Express is about $19.64 \%$, the market share of YTO Express is about $25.43 \%$, the market share of YUNDA Express is about 23.68\%, and the market share of ZTO Express is about $31.25 \%$. Therefore, the market service scale of each express delivery company measured according to the market share is as follows: the market service scale of STO Express is about 3.907 billion pieces, the market service scale of YTO Express is about 5.059 billion pieces, the market service scale of YUNDA Express is about 4.71 billion pieces, and the market service scale of ZTO Express is about 6.219 billion pieces.

According to Table 3, the unit cost of the sharing logistics distribution service is 1.50 yuan/piece, and the cost data is very close to the real urban distribution cost of the express delivery industry. The nonscale economic cost of a sharing logistics distribution company ranges from 0.01 yuan to 0.11 yuan. The transportation cost of intercity logistics of each express delivery company is as follows: the unit transportation cost of STO Express is 1.00 yuan/piece, the unit transportation cost of YTO Express is 1.13 yuan/piece, the unit transportation cost of YUNDA Express is 1.02 yuan/piece, and the unit transportation cost of ZTO Express is 0.93 yuan/piece. These cost data are also very close to the real intercity transportation costs of the express delivery industry.

This paper analyzes the performance optimization strategy of revenue sharing and risk sharing under the circumstances of sharing logistics cooperation between two express delivery companies. Table 1 gives the market size and market share data of each listed express delivery company, and then, we obtain the market demand scale of each express delivery company. According to the model hypothesis and problem setting in this paper, when the two-two cooperation between express delivery companies is solved, the market size will be as shown in Table 4 . There are six sets of data, that is, six kinds of cooperation situations.

Table 5 gives the cost data of each listed express delivery company. According to the research ideas in this paper, any two companies cooperate with each other. Therefore, in 
TABLE 4: Average market size of listed express delivery companies when cooperating two-two.

\begin{tabular}{lcccc}
\hline & STO Express & YTO Express & YUNDA Express & - \\
\hline STO Express & - & - & - & - \\
YTO Express & $a=4482670524$ & - & - & - \\
YUNDA Express & $a=4308366169$ & $a=4884480709$ & $a=5464538177$ \\
ZTO Express & $a=5062727992$ & $a=5638842532$ & - \\
\hline
\end{tabular}

order to distinguish the combination of the unit transportation cost when the two-two express delivery companies share the urban logistics distribution service, the cost data combination will be as shown in Table 5. There are six sets of data, that is, six kinds of cooperation situations.

8.2. Numerical Analysis. The numerical analysis will be developed in three sections: firstly, we analyze the performance improvement of the OFP revenue sharing strategy and the OFP risk sharing strategy when all the express delivery companies cooperate in the two-two sharing logistics; secondly, we compare the advantages and disadvantages of RSF revenue sharing strategy and risk sharing strategy with OFP revenue sharing strategy and risk sharing strategy; finally, we give the comparative results of various performance improvement strategies when the two dimensions' data of nonscale economic cost and combination factor changes.

8.2.1. The Performance of the OFP Supply Chain. In this section, we mainly analyze the changing trends of the total performance of the centralized SC, the decentralized SC, the OFP revenue sharing $\mathrm{SC}$, and the OFP risk sharing $\mathrm{SC}$ when all the express delivery companies cooperate in the two-two sharing logistics and the nonscale economic cost $e$ changes. At the same time, we quantitatively show the degree of performance improvement of OFP revenue sharing strategy and OFP risk sharing strategy. Although the proportion of performance improvement is relatively low, relative to the overall market size of more than 400 billion yuan in the e-commerce express delivery industry, even a $0.4 \%$ performance improvement means a revenue increase of nearly 1.6 billion yuan.

As shown in Table 6, when the nonscale economic costs $e$ change from 0.01 to 0.11 , all the four kinds of supply chain decision-making strategies will decrease with the increase of the cost, that is, the optimal decision is about the monotone decreasing function of nonscale economic cost. And, no matter what the nonscale economic cost is, the overall performance of the OFP revenue sharing supply chain is higher than that of the OFP risk sharing supply chain, which is also between that of the centralized supply chain and the decentralized supply chain. At the same time, it could be seen from the performance improvement data of the above six types of two-two cooperation that the performance improvement of the OFP revenue sharing strategy is roughly between $0.007 \%$ and $0.4 \%$ and that of the OFP risk sharing strategy is roughly between 0 and $0.166 \%$. The change trends are shown in the visual graphs of Figures 2 and 3.
8.2.2. Combined Sharing Factor Supply Chain Performance. In this section, we mainly analyze when the sharing factor combination changes within the range of $0-1$ and the overall performance changing trends of the centralized SC, the decentralized SC, the OFP revenue sharing SC, the OFP risk sharing SC, the RSF revenue sharing SC, and the RSF risk sharing SC of the sharing logistics based on the equity investment.

As shown in Figure 4, when the sharing factor combination changes within the value range $0-1$, in the above several situations, the comparison of the overall performance of the supply chain has undergone significant changes specifically. For example, when the nonscale economic cost $e=0.01$, if the sharing factor $\gamma_{1}$ is taken as follows, there are

(1) When $\gamma_{1} \in\left[0 R_{1}\right), \pi_{\mathrm{sc}}^{c}>\pi_{\mathrm{sc}}^{\mathrm{ref}}>\pi_{\mathrm{sc}}^{\mathrm{rs}}>\pi_{\mathrm{sc}}^{\mathrm{rss}}>\pi_{\mathrm{sc}}^{d}>\pi_{\mathrm{sc}}^{\mathrm{res}}$

(2) When $\gamma_{1} \in\left[R_{1} R_{2}\right), \pi_{\mathrm{sc}}^{c}>\pi_{\mathrm{sc}}^{\mathrm{ref}}>\pi_{\mathrm{sc}}^{\mathrm{rsf}}>\pi_{\mathrm{sc}}^{\mathrm{rss}}>\pi_{\mathrm{sc}}^{\mathrm{res}}>\pi_{\mathrm{sc}}^{d}$

(3) When $\gamma_{1} \in\left[R_{2} R_{3}\right), \pi_{\mathrm{sc}}^{c}>\pi_{\mathrm{sc}}^{\mathrm{ref}}>\pi_{\mathrm{sc}}^{\mathrm{rss}}>\pi_{\mathrm{sc}}^{\mathrm{rsf}}>\pi_{\mathrm{sc}}^{\mathrm{res}}>\pi_{\mathrm{sc}}^{d}$

(4) When $\gamma_{1} \in\left[R_{3} R_{4}\right), \pi_{\mathrm{sc}}^{c}>\pi_{\mathrm{sc}}^{\mathrm{ref}}>\pi_{\mathrm{sc}}^{\mathrm{rss}}>\pi_{\mathrm{sc}}^{\mathrm{res}}>\pi_{\mathrm{sc}}^{\mathrm{rsf}}>\pi_{\mathrm{sc}}^{d}$

(5) When $\gamma_{1} \in\left[R_{4} R_{5}\right), \pi_{\mathrm{sc}}^{c}>\pi_{\mathrm{sc}}^{\mathrm{ref}}>\pi_{\mathrm{sc}}^{\mathrm{res}}>\pi_{\mathrm{sc}}^{\mathrm{rss}}>\pi_{\mathrm{sc}}^{\mathrm{rsf}}>\pi_{\mathrm{sc}}^{d}$

(6) When $\gamma_{1} \in\left[R_{5} R_{6}\right), \pi_{\mathrm{sc}}^{c}>\pi_{\mathrm{sc}}^{\mathrm{res}}>\pi_{\mathrm{sc}}^{\mathrm{ref}}>\pi_{\mathrm{sc}}^{\mathrm{rss}}>\pi_{\mathrm{sc}}^{\mathrm{rsf}}>\pi_{\mathrm{sc}}^{d}$

(7) When $\gamma_{1} \in\left[R_{6} R_{7}\right), \pi_{\mathrm{sc}}^{c}>\pi_{\mathrm{sc}}^{\mathrm{ref}}>\pi_{\mathrm{sc}}^{\mathrm{res}}>\pi_{\mathrm{sc}}^{\mathrm{rss}}>\pi_{\mathrm{sc}}^{\mathrm{rsf}}>\pi_{\mathrm{sc}}^{d}$

(8) When $\gamma_{1} \in\left[R_{7} R_{8}\right), \pi_{\mathrm{sc}}^{c}>\pi_{\mathrm{sc}}^{\mathrm{ref}}>\pi_{\mathrm{sc}}^{\mathrm{rss}}>\pi_{\mathrm{sc}}^{\mathrm{res}}>\pi_{\mathrm{sc}}^{\mathrm{rsf}}>\pi_{\mathrm{sc}}^{d}$

(9) When $\gamma_{1} \in\left[R_{8} R_{9}\right), \pi_{\mathrm{sc}}^{c}>\pi_{\mathrm{sc}}^{\mathrm{ref}}>\pi_{\mathrm{sc}}^{\mathrm{rss}}>\pi_{\mathrm{sc}}^{\mathrm{rsf}}>\pi_{\mathrm{sc}}^{\mathrm{res}}>\pi_{\mathrm{sc}}^{d}$

(10) When $\gamma_{1} \in\left[R_{8} R_{9}\right), \pi_{\mathrm{sc}}^{c}>\pi_{\mathrm{sc}}^{\mathrm{ref}}>\pi_{\mathrm{sc}}^{\mathrm{rsf}}>\pi_{\mathrm{sc}}^{\mathrm{rss}}>\pi_{\mathrm{sc}}^{\mathrm{res}}>\pi_{\mathrm{sc}}^{d}$

(11) When $\gamma_{1} \in\left[R_{10} 1\right), \pi_{\mathrm{sc}}^{c}>\pi_{\mathrm{sc}}^{\mathrm{ref}}>\pi_{\mathrm{sc}}^{\mathrm{rsf}}>\pi_{\mathrm{sc}}^{\mathrm{rss}}>\pi_{\mathrm{sc}}^{d}>\pi_{\mathrm{sc}}^{\mathrm{res}}$

According to Figure 4, the four performance optimization strategies RE-OFP, RS-OFP, RE-RSF, and RS-RSF do not have absolute advantages and disadvantages, but change with the value of the combination sharing factor.

8.2.3. Change Trends of Supply Chain Performance. In this section, we mainly analyze the advantages and disadvantages of several supply chain performance optimization strategies when there is change in both the nonscale economic cost and combination sharing factors. According to Figure 5, for a certain combined sharing factor, as the change of nonscale economic cost, the relationship between several performance optimization strategies changes. For a certain nonscale economic cost, the advantages and disadvantages of several performances between the optimization strategies change with the combined sharing factors. At the same time, in the vast majority of cases, the supply chain performance under the combined sharing factor risk sharing strategy is higher than that under the OFP risk sharing strategy, but is lower than that under the OFP 
TABLE 5: Unit transportation cost combination of two-two cooperation.

\begin{tabular}{lccr}
\hline & STO Express & YTO Express & YUNDA Express \\
\hline STO Express & - & - & - \\
YTO Express & $\left(c_{1}, c_{2}\right)=(1.00,1.13)$ & - & - \\
YUNDA Express & $\left(c_{1}, c_{2}\right)=(1.00,1.02)$ & $\left(c_{1}, c_{2}\right)=(1.13,1.02)$ & - \\
ZTO Express & $\left(c_{1}, c_{2}\right)=(1.00,0.93)$ & $\left(c_{1}, c_{2}\right)=(1.13,0.93)$ & $\left(c_{1}, c_{2}\right)=(1.02,0.93)$ \\
\hline
\end{tabular}

TABLE 6: Change trends of SC performance on the nonscale economic cost $e$ (unit: $10^{18}$ ).

\begin{tabular}{|c|c|c|c|c|c|c|c|c|c|}
\hline & $e$ & 0.01 & 0.03 & 0.05 & 0.07 & 0.09 & 0.11 & Performance ratio (\%) & Performance improvement (\%) \\
\hline \multirow{4}{*}{$\mathrm{STO}+\mathrm{YTO}$} & $\pi_{s c}^{c}$ & 7.5940 & 7.3311 & 7.0891 & 6.8653 & 6.6573 & 6.4633 & - & - \\
\hline & $\pi_{s c}^{d}$ & 7.5932 & 7.3256 & 7.0765 & 6.8443 & 6.6275 & 6.4246 & 99.401-99.989 & - \\
\hline & $\pi_{\mathrm{sc}}^{\mathrm{ref}}$ & 7.5938 & 7.3296 & 7.0854 & 6.8587 & 6.6476 & 6.4502 & 99.797-99.997 & $0.008-0.396$ \\
\hline & $\pi_{\mathrm{sc}}^{\mathrm{rsf}}$ & 7.5935 & 7.3275 & 7.0805 & 6.8506 & 6.6360 & 6.4351 & 99.564-99.993 & $0.004-0.163$ \\
\hline \multirow{4}{*}{ STO + YUNDA } & $\pi_{s c}^{c}$ & 7.0149 & 6.7720 & 6.5485 & 6.3418 & 6.1496 & 5.9704 & - & - \\
\hline & $\pi_{s c}^{d e}$ & 7.0142 & 6.7670 & 6.5369 & 6.3224 & 6.1221 & 5.9347 & 99.402-99.990 & - \\
\hline & $\pi_{\mathrm{sc}}^{\mathrm{sc}}$ & 7.0147 & 6.7706 & 6.5451 & 6.3357 & 6.1407 & 5.9583 & 99.797-99.997 & $0.007-0.395$ \\
\hline & $\pi_{\mathrm{sc}}^{\mathrm{rs}}$ & 7.0144 & 6.7687 & 6.5406 & 6.3282 & 6.1299 & 5.9444 & $99.565-99.993$ & $0.003-0.163$ \\
\hline \multirow{4}{*}{$\mathrm{STO}+\mathrm{ZTO}$} & $\pi_{s c}^{c}$ & 9.6864 & 9.3511 & 9.0425 & 8.7570 & 8.4916 & 8.2442 & - & - \\
\hline & $\pi_{\mathrm{sc}}^{s^{d}}$ & 9.6855 & 9.3442 & 9.0264 & 8.7302 & 8.4536 & 8.1948 & 99.401-99.991 & - \\
\hline & $\pi_{\mathrm{sc}}^{\mathrm{ref}}$ & 9.6862 & 9.3492 & 9.0377 & 8.7486 & 8.4793 & 8.2275 & 99.797-99.998 & $0.007-0.396$ \\
\hline & $\pi_{\mathrm{sc}}^{\mathrm{sc}}$ & 9.6858 & 9.3465 & 9.0315 & 8.7382 & 8.4645 & 8.2082 & 99.563-99.994 & $0.003-0.162$ \\
\hline \multirow{4}{*}{ YTO + YUNDA } & $\pi_{\mathrm{sc}}^{c}$ & 9.0164 & 8.7042 & 8.4170 & 8.1512 & 7.9042 & 7.6739 & - & - \\
\hline & $\pi_{\mathrm{sc}}^{d}$ & 9.0155 & 8.6978 & 8.4020 & 8.1263 & 7.8688 & 7.6280 & $99.402-99.990$ & - \\
\hline & $\pi_{\mathrm{sc}}^{\mathrm{sc}}$ & 9.0161 & 8.7024 & 8.4125 & 8.1434 & 7.8927 & 7.6583 & 99.797-99.997 & $0.007-0.395$ \\
\hline & $\pi_{\mathrm{sc}}^{\mathrm{sc}}$ & 9.0158 & 8.7000 & 8.4068 & 8.1338 & 7.8789 & 7.6404 & $99.563-99.993$ & $0.003-0.161$ \\
\hline \multirow{4}{*}{ YTO + ZTO } & $\pi_{\mathrm{sc}}^{c}$ & 12.016 & 11.600 & 11.218 & 10.863 & 10.534 & 10.227 & - & - \\
\hline & $\pi_{s c}^{d}$ & 12.015 & 11.592 & 11.198 & 10.830 & 10.487 & 10.166 & 99.404-99.992 & - \\
\hline & $\pi_{\mathrm{sc}}^{\mathrm{ref}}$ & 12.016 & 11.598 & 11.212 & 10.853 & 10.519 & 10.207 & 99.804-100 & $0.008-0.4$ \\
\hline & $\pi_{\mathrm{sc}}^{\mathrm{rsf}}$ & 12.016 & 11.595 & 11.204 & 10.840 & 10.501 & 10.183 & 99.570-100 & $0.008-0.166$ \\
\hline \multirow{4}{*}{ YUNDA + ZTO } & $\pi_{s c}^{c}$ & 11.285 & 10.894 & 10.535 & 10.202 & 9.893 & 9.605 & - & - \\
\hline & $\pi_{s c}^{d c}$ & 11.284 & 10.886 & 10.516 & 10.171 & 9.849 & 9.547 & 99.396-99.991 & - \\
\hline & $\pi_{\mathrm{sc}}^{\mathrm{sc}}$ & 11.285 & 10.892 & 10.529 & 10.192 & 9.879 & 9.585 & $99.792-100$ & $0.009-0.396$ \\
\hline & $\pi_{\mathrm{sc}}^{\mathrm{sc}}$ & 11.284 & 10.889 & 10.522 & 10.180 & 9.861 & 9.563 & 99.563-99.991 & $0-0.167$ \\
\hline
\end{tabular}

Performance ratio represents the proportion of the supply chain performance in the other situations to that in the centralized situation. Performance improvement represents the improvement ratio of the supply chain performance in the other situations to that in the centralized situation.

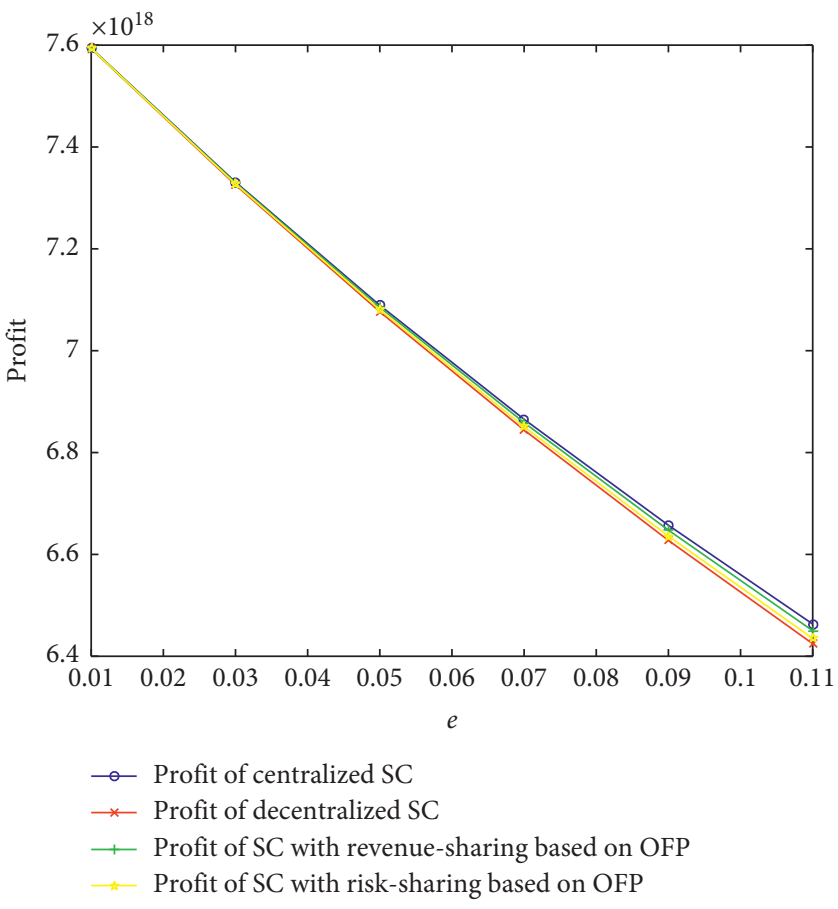

FIGURE 2: SC performance under the cooperation of STO and YTO with the change trend of nonscale economic cost $e$. 


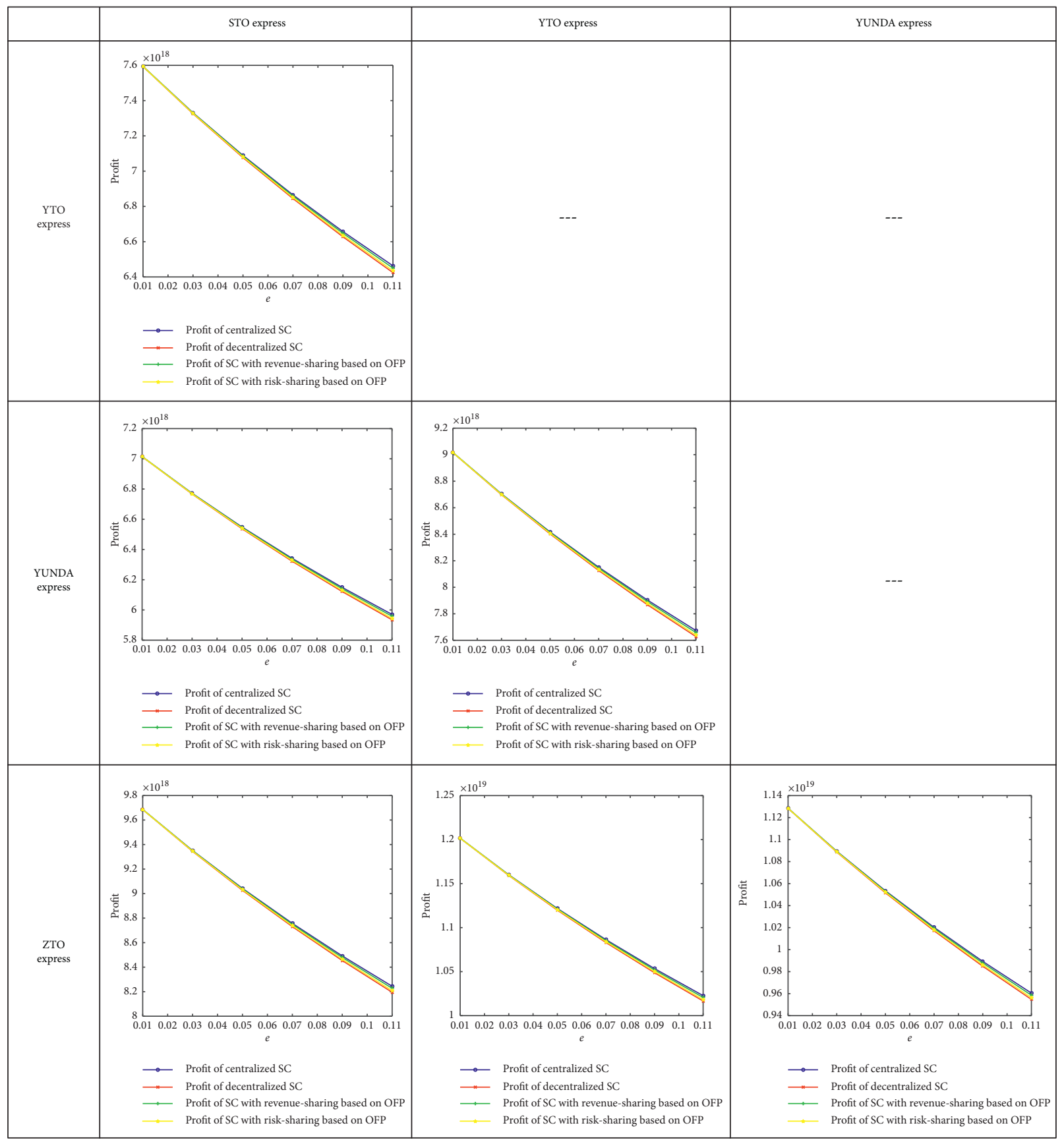

FIgURE 3: SC performance during the two-two cooperation on the change trends of nonscale economic cost $e$.

revenue sharing strategy. If the value of the combined sharing factor is too high or too low, which means the value is too close to 0 or 1 , supply chain performance under a combined sharing factor revenue sharing strategy may be lower than the overall performance under the decentralized supply chain.

\section{Theoretical and Managerial Implications}

9.1. Theoretical Implications. There are two types of sharing distribution: vertical sharing and horizontal sharing. For vertical sharing, distribution is often organized along modes and service operators. For instance, the first leg within the city may be carried out by conventional trucks, whereas the last mile to the recipient may be operated by environment-friendly city freighters. In horizontal sharing, multiple providers work together in the same section of the distribution chain, potentially sharing orders and infrastructure [1]. The previous scholars' research on the sharing logistics distribution mainly focuses on the distribution method. In contrast, only fewer scholars consider the serious problems that hinder the promotion of sharing distribution in practice, such as the construction process of the sharing distribution 


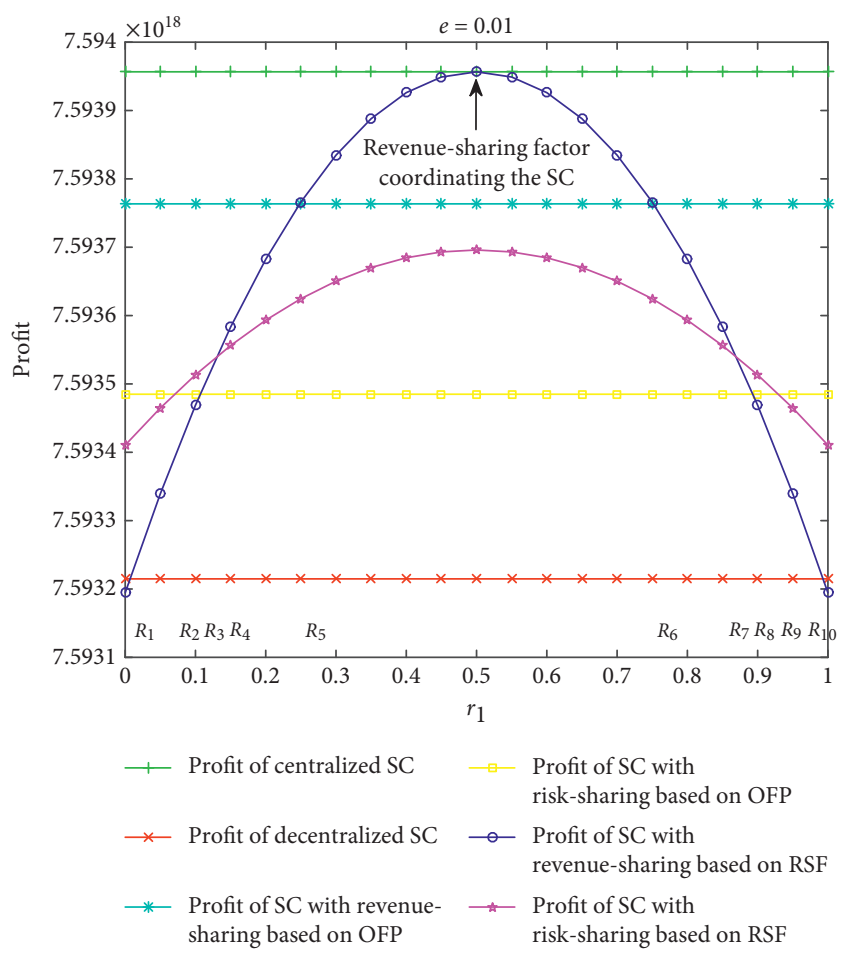

FIgURE 4: Change trends of the SC performance on the combined sharing factors.

cooperative organization, specific operation methods, coordination and supervision, and establishment of incentive mechanisms, as well as establishment of trust mechanisms. Further obstacles include low load factors, empty trips, long dwell times at loading and unloading points, and large numbers of deliveries to individual customers [35]. The horizontal and vertical transportation alliances are too loose and have many of the aforementioned drawbacks. Therefore, the equity investment-based model proposed in this paper further strengthens the cooperation depth of transportation alliances and enhances its operability in commercial practice. We make interviews and exchanges with many top-class logistics enterprises and e-commerce logistics enterprises, then summarize and refine the characteristics of business-based equity cooperation projects, which often occur in modern logistics industry, and design the equity-based sharing logistics distribution cooperation mechanism based on this.

\subsection{Managerial Implications}

9.2.1. Vertical and Horizontal Integration. Different from the exogenous vertical integration, for example, extending from iron ore smelting to the production of finished steel products, the express delivery companies obtain logistics orders from online e-commerce enterprises that need to be finally delivered to end e-commerce customers, but only self-operate intercity logistics transportation and outsource the urban logistics distribution business to professional urban distribution companies. In this case, if the express delivery companies extend the development of the urban logistics distribution business based on the vertical integration strategy adopted by the logistics order that one has already mastered, this is an endogenous vertical integration strategy. Compared with exogenous vertical integration, the biggest advantage of endogeneity is that it does not need to redevelop a new customer market, but it can better provide existing e-commerce enterprises and customers with more value-added services. Obviously, the sharing logistics mechanisms that we propose in this paper belong to the endogenous vertical integration.

9.2.2. Income Distribution Mechanism. Due to the imbalance of market power among supply chain members, there are often many obstacles in implementing traditional supply chain coordination mechanisms among supply chain members, and there is also a lack of necessary institutional mechanism guarantees. The combination contract mechanism of supply chain coordination and equity investment proposed in this paper can solve the problem fundamentally from the interests of all parties and greatly improve the feasibility of the implementation of the sharing logistics cooperation mechanism. At the same time, we have also analyzed and compared the equity cooperation 

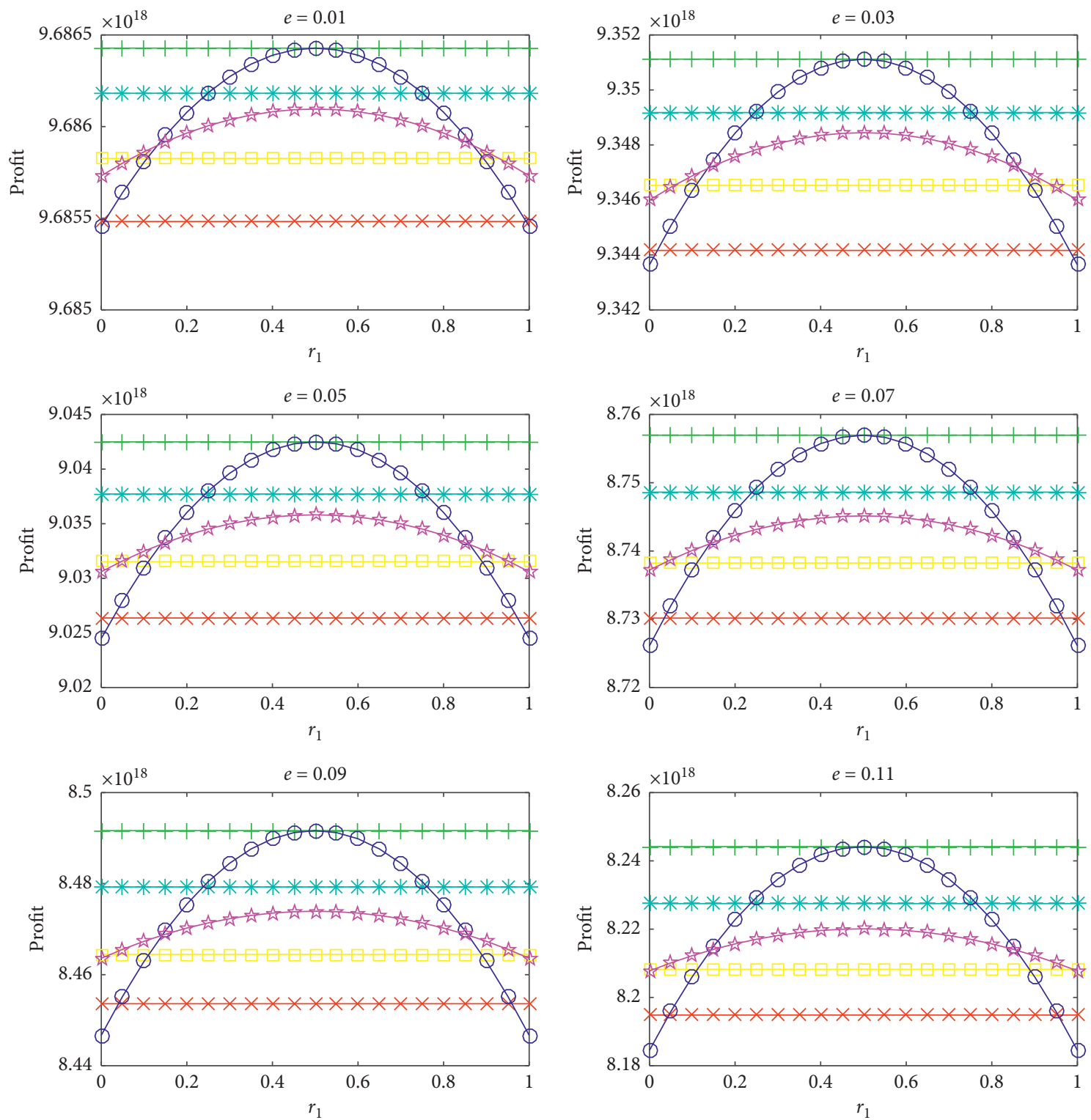

FIGURE 5: Change trends of the SC performance on combined sharing factors and nonscale economic cost. (a) $e=0.01$. (b) $e=0.03$. (c) $e=0.05$. (d) $e=0.07$. (e) $e=0.09$. (f) $e=0.11$.

mechanisms of revenue sharing and risk sharing. The study found that equity cooperation based on the proportion of order flow is more conducive to the achievement and sustainable development of the sharing cooperation mechanism. This also explains theoretically why is the order flow charge gradually becoming a benefit distribution mechanism often used in the practice of logistics operations, instead of the traditional fixed equity proportional distribution mechanism. This equity cooperation and revenue distribution mechanism based on the proportion of order flow is similar to the TUP mechanism design of Huawei and others. 


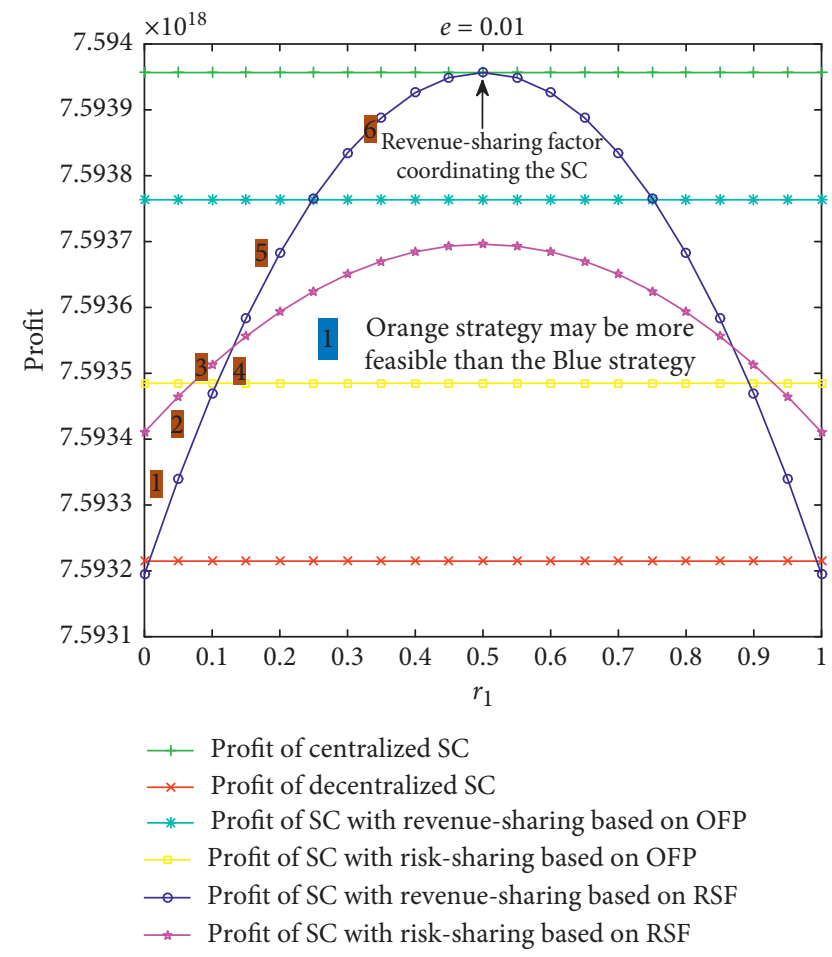

FIGURE 6: The optimization strategy cannot be completed in one step, but step by step

\section{Conclusions}

In this paper, we study the sharing logistics cooperation mechanism under the condition of random demand considering the undersupply and oversupply of the express delivery service, and we compare and analyze the revenue sharing contract and risk sharing contract based on equity investment cooperation. Moreover, by using the recent financial report data of several listed express delivery companies in China, we carry out the numerical analysis of the main research conclusions and results and give the analysis and comparison results of relevant visualizations. The research results show that when faced with the stochastic market demand, in the case of comprehensive consideration of undersupply and oversupply of express delivery services, revenue sharing and risk sharing strategies based on the OFP and RSF both have better feasible space than decentralized supply chain of the sharing logistics. When the combined sharing factor approaches 0.5 , which means the benefit sharing is evenly distributed, the revenue sharing mechanism and the risk sharing mechanism based on the combined sharing factor are better than those based on the OFP.
There are certain revenue sharing factors that make the supply chain performance under the revenue sharing mechanism very close to or even equal to the overall performance under the centralized supply chain.

In the real e-commerce express operation environment, the market demand of each express delivery company is not only related to the price of the express delivery service of the company but also affected by the service price of other express delivery companies, which is a perturbed type of price-dependent demand structure. At the same time, we should also consider the risk of undersupply and oversupply of express delivery services due to unpredictable market demand or high prediction difficulty and low prediction accuracy. Therefore, an optimization model that comprehensively considers the price disturbance-type stochastic demand and the undersupply and oversupply risk loss will be the key content of the next research process. At the same time, under the premise that scientific decision-making has been formulated, how to carry out gradual practice optimization instead of blindly implementing policies and making one step at a time will be another problem in the following research. Looking to the future, we should have a clearer understanding that most optimization decisions of management science only give the good results that we want to achieve in the end. However, we do not give an implementation strategy of how to reach the end point step by step. In reality, there are too many obstacles to solve the problem at once. Therefore, a step-by-step strategy similar to the "gradient descent method" may have a stronger practical guiding significance (Figure 6).

\section{Appendix}

\section{A. Proof of Proposition 1}

Solving the first and second derivative of the total revenue decision in turn, they are as follows:

$$
\begin{aligned}
\frac{\partial \pi_{\mathrm{sc}}^{c}}{\partial q_{i}} & =-c-2 e \sum_{i=1}^{2} q_{i}+\frac{3 q_{i}^{2}}{2 a}-\frac{q_{i}}{a}\left(3 a-c_{i}-v+k\right)+a-c_{i}+k, \\
\frac{\partial^{2} \pi_{\mathrm{sc}}^{c}}{\partial q_{i}^{2}} & =-2 e+\frac{-3\left(a-q_{i}\right)+c_{i}+v-k}{a}<0, \\
\frac{\partial^{2} \pi_{\mathrm{sc}}^{c}}{\partial q_{i} \partial q_{j}} & =\frac{\partial^{2} \pi_{\mathrm{sc}}^{c}}{\partial q_{j} \partial q_{i}}=-2 e<0 .
\end{aligned}
$$

Furthermore, the solution of the Hesse determinant is 


$$
\begin{aligned}
\mathrm{H}_{2}=\left|\begin{array}{cc}
\frac{\partial^{2} \pi_{\mathrm{sc}}^{c}}{\partial q_{1}^{2}} & \frac{\partial^{2} \pi_{\mathrm{sc}}^{c}}{\partial q_{1} \partial q_{2}} \\
\frac{\partial^{2} \pi_{\mathrm{sc}}^{c}}{\partial q_{2} \partial q_{1}} & \frac{\partial^{2} \pi_{\mathrm{sc}}^{c}}{\partial q_{2}^{2}}
\end{array}\right|=\left|\begin{array}{cc}
-2 e+\frac{-3\left(a-q_{1}\right)+c_{1}+v-k}{a} & -2 e \\
-2 e & -2 e+\frac{-3\left(a-q_{2}\right)+c_{2}+v-k}{a}
\end{array}\right| \\
=-2 e \times \frac{-3\left(a-q_{1}\right)-3\left(a-q_{2}\right)+c_{1}+c_{2}+2 v-2 k}{a}+\frac{-3\left(a-q_{1}\right)+c_{1}+v-k}{a} \times \frac{-3\left(a-q_{2}\right)+c_{2}+v-k}{a}>0 .
\end{aligned}
$$

Hence, it is known from $\left(\partial^{2} \pi_{\mathrm{sc}}^{c} / \partial q_{i}^{2}\right)<0, \forall i=1$ and 2 and $\mathrm{H}_{2}>0$, that the centralized decision function has an optimal solution and satisfies the above first-order conditional expression. The proof of the formula is completed.

\section{B. Proof of Proposition 2}

Solving the first and second derivatives of the revenue function of the express delivery company $i$ as follows:

$$
\begin{aligned}
\frac{\mathrm{d} \pi_{i}^{d 2}}{\mathrm{~d} q_{i}}= & \frac{3 q_{i}^{2}}{2 a}-\frac{q_{i}}{a}\left(3 a-c_{i}-v+k\right) \\
& +\left(a-c_{i}+k-c-2 e \sum_{j=1}^{2} q_{j}\right)-2 e q_{i}, \\
\frac{\mathrm{d}^{2} \pi_{i}^{d 2}}{\mathrm{~d} q_{i}^{2}}= & \frac{3 q_{i}}{a}-\frac{1}{a}\left(3 a-c_{i}-v+k\right)-4 e \\
= & -\frac{3}{a}\left(a-q_{i}\right)+\frac{c_{i}+v-k}{a}-4 e<0 .
\end{aligned}
$$

It could be seen from $\left(\mathrm{d}^{2} \pi_{i}^{d 2} / \mathrm{d} q_{i}^{2}\right)<0$ that there is an optimal response function of each express delivery company to the purchase order quantity of other express delivery companies. The optimal decision can be obtained by solving the intersection of these optimal response functions, that is, to say the equilibrium point.

\section{Proof of Proposition 3}

Firstly, we solve the first and second derivatives of the revenue function of the express delivery company $i$ :

$$
\begin{aligned}
\frac{\mathrm{d} \pi_{i}^{\mathrm{ref}}}{\mathrm{d} q_{i}}= & \frac{3 q_{i}^{2}}{2 a}-\frac{q_{i}}{a}\left(3 a-c_{i}-v+k\right) \\
& +\left(a-c_{i}+k-c-e \sum_{j=1}^{2} q_{j}\right)-e q_{i}, \\
\frac{\mathrm{d}^{2} \pi_{i}^{\mathrm{ref}}}{\mathrm{d} q_{i}^{2}}= & \frac{3 q_{i}}{a}-\frac{1}{a}\left(3 a-c_{i}-v+k\right)-2 e \\
= & -\frac{3}{a}\left(a-q_{i}\right)+\frac{c_{i}+v-k}{a}-2 e<0 .
\end{aligned}
$$

It could be known from $\left(\mathrm{d}^{2} \pi_{i}^{\mathrm{ref}} / \mathrm{d} q_{i}^{2}\right)<0$ that there is an optimal response function of each express delivery company to the purchase order quantity of other express delivery companies. It is only required to solve the intersection point of these optimal reaction functions, that is, the equilibrium point, and then, the optimal decision could be obtained.

\section{Proof of Proposition 4}

Firstly, we solve the first and second derivatives of the revenue function of the express delivery company $i$ :

$$
\begin{gathered}
\frac{\mathrm{d} \pi_{i}^{\mathrm{res}}}{\mathrm{d} q_{i}}=\frac{3 q_{i}^{2}}{2 a}-\frac{q_{i}}{a}\left(3 a-c_{i}-v+k\right)+\left(a-c_{i}+k-c-2 e \sum_{j=1}^{2} q_{j}\right)-2 e q_{i}+2 \gamma_{i}^{\mathrm{res}} e \sum_{j=1}^{2} q_{j}, \\
\frac{\mathrm{d}^{2} \pi_{i}^{\mathrm{res}}}{\mathrm{d} q_{i}^{2}}=\frac{3 q_{i}}{a}-\frac{1}{a}\left(3 a-c_{i}-v+k\right)-4 e+2 \gamma_{i}^{\mathrm{res}} e=-\frac{3}{a}\left(a-q_{i}\right)+\frac{c_{i}+v-k}{a}-4 e+2 \gamma_{i}^{\mathrm{res}} e<0 .
\end{gathered}
$$

It could be known from $\left(\mathrm{d}^{2} \pi_{i}^{\mathrm{res}} / \mathrm{d} q_{i}^{2}\right)<0$ that there is an optimal response function of each express delivery company to the purchase order quantity of other express delivery companies. It is only required to solve the intersection point of these optimal reaction functions, that is, the equilibrium point, and the optimal decision can be obtained. 


\section{E. Proof of Proposition 5}

Firstly, we calculate the first derivative and the second derivative of the revenue function of express company $i$ :

$$
\begin{aligned}
\frac{\mathrm{d} \pi_{i}^{\mathrm{rsf}}}{\mathrm{d} q_{i}}= & -c-4 e q_{i}+\frac{(3+6 e) q_{i}^{2}}{2 a}-\frac{q_{i}}{a}\left(3 a-c-c_{i}-2 e q_{j}\right)+a-c_{i}-2 e q_{j} \\
& -\frac{q_{j}}{\left(q_{i}+q_{j}\right)^{2}} \sum_{j=1}^{2}\left[\frac{q_{j}^{2}}{2 a}\left(c-v+k+2 e \sum_{j=1}^{2} q_{j}\right)-k q_{j}+\frac{a k}{2}\right] \\
& -\frac{q_{i}}{q_{i}+q_{j}}\left[\frac{q_{i}\left(c-v+k+2 e \sum_{j=1}^{2} q_{j}\right)}{a}-k+\frac{e\left(q_{i}^{2}+q_{j}^{2}\right)}{a}\right], \frac{\mathrm{d}^{2} \pi_{i}^{\mathrm{rsf}}}{\mathrm{d} q_{i}^{2}}=\frac{3 q_{i}}{a}-\frac{1}{a}\left(3 a-c-c_{i}-2 e \sum_{j=1}^{2} q_{j}\right)+\frac{4 e q_{i}}{a}-4 e \\
& -\frac{2 q_{j} \sum_{j=1}^{2} q_{j}}{\left(q_{i}+q_{j}\right)^{4}} \sum_{j=1}^{2}\left[\frac{q_{j}^{2}}{2 a}\left(c-v+k+2 e \sum_{j=1}^{2} q_{j}\right)-k q_{j}+\frac{a k}{2}\right]-\frac{2 q_{j}}{\left(q_{i}+q_{j}\right)^{2}}\left[\frac{q_{i}\left(c-v+k+2 e \sum_{j=1}^{2} q_{j}\right)}{a}-k+\frac{e\left(q_{i}^{2}+q_{j}^{2}\right)}{a}\right] \\
& -\frac{q_{i}}{q_{i}+q_{j}}\left(\frac{c-v+k+2 e \sum_{j=1}^{2} q_{j}+4 e q_{i}}{a}\right)<0 .
\end{aligned}
$$

It could be known from $\left(\mathrm{d}^{2} \pi_{i}^{\mathrm{rsf}} / \mathrm{d} q_{i}^{2}\right)<0$ that there is an optimal response function of each express delivery company to the purchase order quantity of other express delivery companies. It is only required to solve the intersection point of these optimal reaction functions, that is, the equilibrium point, and then, the optimal decision can be obtained.

\section{F. Proof of Proposition 6}

Firstly, we solve the first and second derivatives of the revenue function of the express delivery company $i$ :

$$
\begin{aligned}
\frac{\mathrm{d} \pi_{i}^{\mathrm{rss}}}{\mathrm{d} q_{i}}= & -c-4 e q_{i}+\frac{(3+6 e) q_{i}^{2}}{2 a}-\frac{q_{i}}{a}\left(3 a-c_{i}-c-2 e q_{j}\right) \\
& +a-c_{i}-2 e q_{j}-\gamma_{i}^{\mathrm{rss}}\left[\frac{q_{i}\left(c-v+k+2 e \sum_{j=1}^{2} q_{j}\right)}{a}-k+\frac{e\left(q_{i}^{2}+q_{j}^{2}\right)}{a}\right], \\
\frac{\mathrm{d}^{2} \pi_{i}^{\mathrm{rss}}}{\mathrm{d} q_{i}^{2}}= & \frac{3 q_{i}}{a}-\frac{1}{a}\left(3 a-c_{i}-c-2 e \sum_{j=1}^{2} q_{j}\right) \\
& +\frac{4 e q_{i}}{a}-4 e-\gamma_{i}^{\mathrm{rss}}\left(\frac{c-v+k+2 e \sum_{j=1}^{2} q_{j}+4 e q_{i}}{a}\right)<0 .
\end{aligned}
$$

It could be known from $\left(\mathrm{d}^{2} \pi_{i}^{\mathrm{rss}} / \mathrm{d} q_{i}^{2}\right)<0$ that there is an optimal response function of each express delivery company to the purchase order quantity of other express delivery companies. It is only required to solve the intersection point of these optimal reaction functions, that is, the equilibrium point, and the optimal decision can be obtained. 


\section{Data Availability}

The data used to support the findings of the study are available from the corresponding author upon reasonable request.

\section{Conflicts of Interest}

The authors declare that they have no conflicts of interest.

\section{Acknowledgments}

This research was supported by Fundamental Research Funds for the Central Universities (JBK1507105).

\section{References}

[1] C. Catherine, C. Caitlin, F. E. Jan, and T. Kevin, "Collaborative urban transportation: recent advances in theory and practice," European Journal of Operational Research, vol. 273, no. 3, pp. 801-816, 2019.

[2] I. Giannoccaro and P. Pontrandolfo, "Negotiation of the revenue sharing contract: an agent-based systems approach," International Journal of Production Economics, vol. 122, no. 2, pp. 558-566, 2009.

[3] W. Liu, C. Liu, and M. Ge, "An order allocation model for the two-echelon logistics service supply chain based on cumulative prospect theory," Journal of Purchasing and Supply Management, vol. 19, no. 1, pp. 39-48, 2013.

[4] W. Liu, Q. Wang, Q. Mao, S. Wang, and D. Zhu, "A scheduling model of logistics service supply chain based on the mass customization service and uncertainty of FLSP's operation time," Transportation Research Part E: Logistics and Transportation Review, vol. 83, pp. 189-215, 2015.

[5] W. Liu, Z. Liang, Z. Ye, and L. Liu, "The optimal decision of customer order decoupling point for order insertion scheduling in logistics service supply chain," International Journal of Production Economics, vol. 175, pp. 50-60, 2016.

[6] T. Bektas, T. G. Crainic, and T. Van Woensel, "From managing urban freight to smart city logistics networks," in Network Design and Optimization for Smart Cities, pp. 143188, World Scientifific, Singapore, 2017.

[7] M. Savelsbergh and T. Van Woensel, "50th anniversary invited article-city logistics: challenges and opportunities," Transportation Science, vol. 50, no. 2, pp. 579-590, 2016.

[8] R. G. Thompson and K. P. Hassall, "A collaborative urban distribution network," Procedia - Social and Behavioral Sciences, vol. 39, pp. 230-240, 2012.

[9] M. Browne, J. Allen, T. Nemoto, D. Patier, and J. Visser, "Reducing social and environmental impacts of urban freight transport: a review of some major cities," Procedia-Social and Behavioral Sciences, vol. 39, pp. 19-33, 2012.

[10] D. Cattaruzza, N. Absi, D. Feillet, and J. González-Feliu, "Vehicle routing problems for city logistics," EURO Journal on Transportation and Logistics, vol. 6, no. 1, pp. 51-79, 2015.

[11] C. Narasimhan, P. Papatla, and P. Ravula, "Preference segmentation induced by tariff schedules and availability in ridesharing markets," University of Wisconsin-Milwaukee, Milwaukee, WI, USA, Working study, 2016.

[12] C. Wu, Y. Wang, and T. Zhu, "Mobile hailing technology, worker productivity and digital inequality: a case of the taxi industry," The University of British Columbia, Vancouver, Canada, Working study, 2016.
[13] G. Zervas, D. Proserpio, and J. W. Byers, "The rise of the sharing economy: estimating the impact of Airbnb on the hotel industry," Journal of Marketing Research, vol. 54, no. 5, pp. 687-705, 2017.

[14] P. Cohen, R. W. Hahn, J. Hall, S. D. Levitt, and R. D. Metcalfe, "Using big data to estimate consumer surplus: the case of uber," Nber Working Studys, National Bureau of Economic Research, Cambridge, MA, USANational Bureau of Economic Research, 2016.

[15] L. Tian and B. Jiang, "Effects of consumer-to-consumer product sharing on distribution channel," Production \& Operations Management, vol. 27, no. 3, 2018.

[16] H. Guda and U. Subramanian, Strategic Surge Pricing and Forecast Communication on On-Demand Service Platforms, Social Science Electronic Publishing, Rochester, NY, USA, 2017.

[17] R. Belk, "Sharing," Journal of Consumer Research, vol. 36, no. 5, pp. 715-734, 2010.

[18] S. Ranchordás, "Does sharing mean caring: regulating innovation in the sharing economy," Minnesota Journal of Law, Science and Technology, vol. 16, no. 1, p. 413, 2015.

[19] P. He, Y. He, C. Shi, H. Xu, and L. Zhou, "Cost-sharing contract design in a low-carbon service supply chain," Computers \& Industrial Engineering, vol. 139, Article ID 106160, 2020.

[20] G. P. Cachon and M. A. Lariviere, "Supply chain coordination with revenue-sharing contracts: strengths and limitations," Management Science, vol. 51, no. 1, pp. 30-44, 2005.

[21] Y.-Y. Wang, H.-S. Lau, and Z.-S. Hua, "Three revenue-sharing variants: their significant performance differences under system-parameter uncertainties," Journal of the Operational Research Society, vol. 63, no. 12, pp. 1752-1764, 2012.

[22] Q. Wei, S. Li, X. Gou, and B. Huo, "Joint optimal decision of the shared distribution system through revenue-sharing and cooperative investment contracts," Industrial Management \& Data Systems, vol. 119, no. 3, pp. 578-612, 2019.

[23] J. Zhang, G. Liu, Q. Zhang, and Z. Bai, “Coordinating a supply chain for deteriorating items with a revenue sharing and cooperative investment contract," Omega, vol. 56, pp. 37-49, 2015.

[24] Q. Bai, M. Chen, and L. Xu, "Revenue and promotional costsharing contract versus two-part tariff contract in coordinating sustainable supply chain systems with deteriorating items," International Journal of Production Economics, vol. 187, pp. 85-101, 2017.

[25] B. $\mathrm{Hu}, \mathrm{D} . \mathrm{Xu}$, and C. Meng, "Inconsistency of a retailer's optimal policies and channel performance under revenue sharing contracts," International Journal of Production Economics, vol. 183, pp. 53-65, 2017.

[26] H. Yang, J. Luo, and H. Wang, "The role of revenue sharing and first-mover advantage in emission abatement with carbon tax and consumer environmental awareness," International Journal of Production Economics, vol. 193, pp. 691-702, 2017.

[27] H. Song and X. Gao, "Green supply chain game model and analysis under revenue-sharing contract," Journal of Cleaner Production, vol. 170, pp. 183-192, 2018.

[28] H. Yang and W. Chen, "Retailer-driven carbon emission abatement with consumer environmental awareness and carbon tax: revenue-sharing versus Cost-sharing," Omega, vol. 78, pp. 179-191, 2018.

[29] T. Li, R. Zhang, S. Zhao, and B. Liu, "Low carbon strategy analysis under revenue-sharing and cost-sharing contracts," Journal of Cleaner Production, vol. 212, pp. 1462-1477, 2019. 
[30] B. Yu, J. Wang, X. Lu, and H. Yang, "Collaboration in a lowcarbon supply chain with reference emission and cost learning effects: cost sharing versus revenue sharing strategies," Journal of Cleaner Production, vol. 250, Article ID 119460, 2010.

[31] Y. He, F. Zhou, M. Qi, and X. Wang, "Joint distribution: service paradigm, key technologies and its application in the context of Chinese express industry," International Journal of Logistics Research and Applications, vol. 23, no. 3, pp. 211-227, 2020.

[32] D. Xiao, J. Wang, and Q. Lu, "Stimulating sustainability investment level of suppliers with strategic commitment to price and cost sharing in supply chain," Journal of Cleaner Production, vol. 252, Article ID 119732, 2020.

[33] F. L. Yun, Y. Wang, and Y. Wu, "Consignment contracts with revenue sharing for a capacitated retailer and multiple manufacturers," Manufacturing \& Service Operations Management, vol. 17, no. 4, pp. 527-537, 2012.

[34] Y. Luo, Q. Wei, X. Gou, D. Dai, and Y. Zhou, "Sharing logistics service supply chain with revenue-sharing vs. costsharing contracts," Mathematical Problems in Engineering, vol. 2021, Article ID 8841536, 31 pages, 2021.

[35] E. M. Cepolina and A. Farina, "A new urban freight distribution scheme and an optimization methodology for reducing its overall cost," European Transport Research Review, vol. 7, no. 1, pp. 1-14, 2015. 